\title{
WS.B (Usabtis)
}

FÉlix Alonso y Royano *

RESUMEN ABSTRACT

Estudio, clasificación e interpretación de las figurillas finerarias egipcias denominadas WS.B. Usabtis.

DEDICATORIA

Este trabajo está dedicado a mis hijos: José Félix, Laura, Javier y Eduardo.
Study, clasification and interpretation of funeraries egypties figures used on funerary tithes named WS.B. Usabtis.

\section{DEDICATORY}

This work is dedicated to my songs: José Félix, Laura, Javier and Eduardo.

\section{ÍNDICE}

1. ESQUEMA ELEMENTAL DE LOS USABTIS.

2. LOS USABTIS EN EL TRANSCURSO DEL TIEMPO.

3. LA «JUSTIFICACIÓN» PASO PREVIO A LA DISPONIBILIDAD DEL USABTIS.

A) EL "ORDEN CÓSMICO»: M3ÇT.

B) EL JEROGLÍFICO M3ÇT.

\footnotetext{
* Doctor en Derecho. Egiptólogo de la Fondation Égyptologique. Reine Elisabeth. Bruxelles. Profesor Tutor de la UNED. CAB.
} 

C) ANUBIS.
D) TOTH.
E) $A M M I T$.
F) OSIRIS.

4. EPILOGO.

5. BIBLIOGRAFÍA NO EXHAUSTIVA.

\section{ESQUEMA ELEMENTAL DE LOS USABTIS}



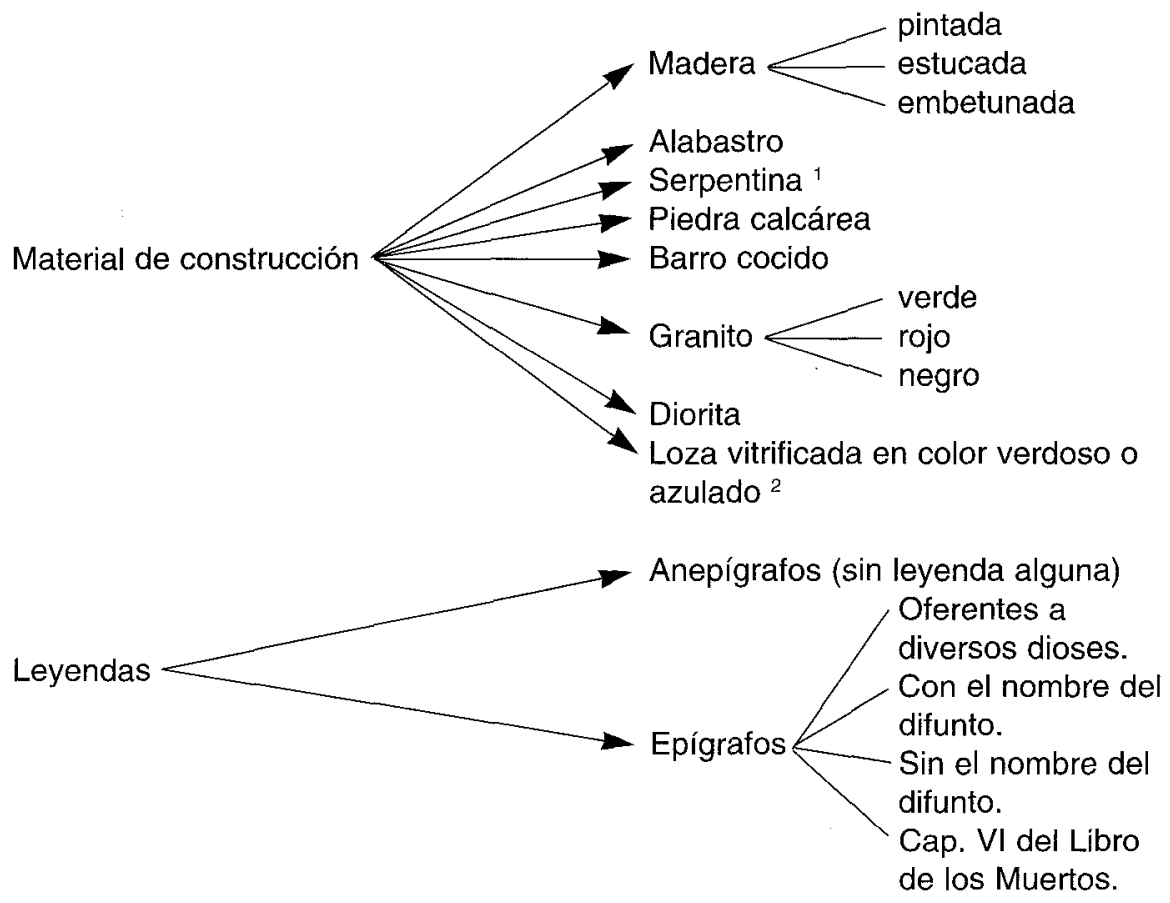

Soporte escriturario $\longrightarrow$ Giabado a incisión

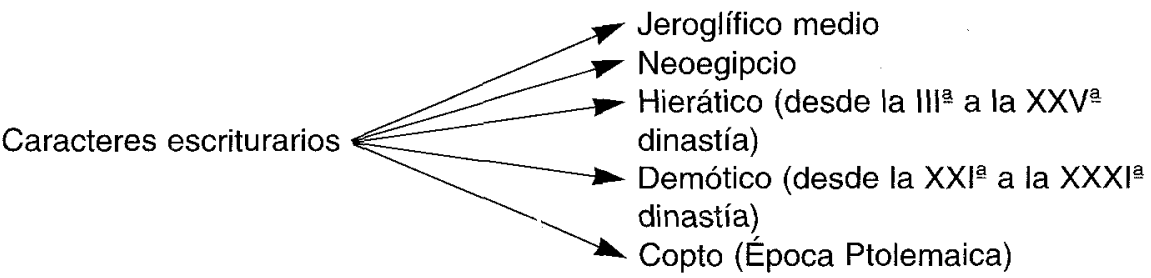

1 Roca compacta constituida en su mayor parte por antigorita de color verde con manchas o vetas negras y lustre craso con un buen pulimento.

2 Lo que los franceses y belgas denominan «faïence» es un compuesto de arena fina cementada con silicato sódico que forma un carbonato o bicarbonato de sodio que era frecuentemente explotado en Uadi Natrum, de modo que unos pocos gramos de óxido de cobre hacen que esa «faïence» presente un bonito color azul o verdoso que forma, a partir de una temperatura de $950^{\circ}$, una capa vítrea en su superficie. Algunos de los usabtis de la colección particular del autor que se presentan en este trabajo, son de ese material. 


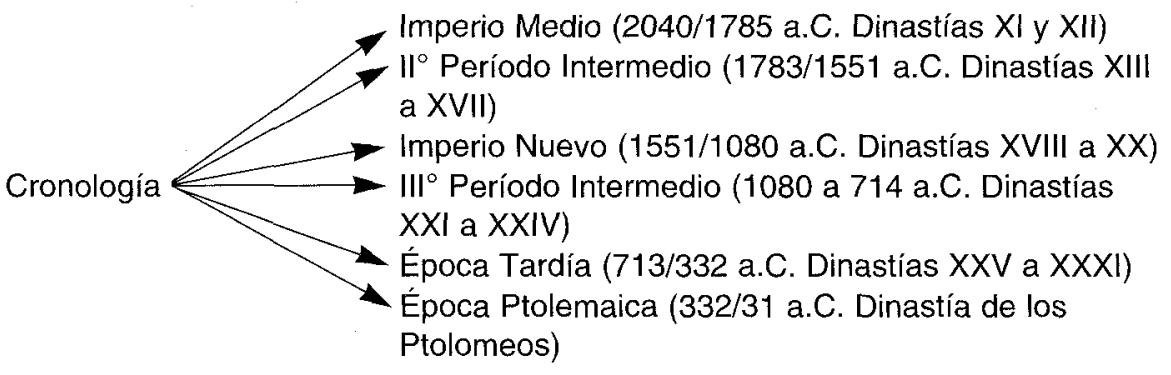

\section{LOS USABTIS EN EL TRANSCURSO DEL TIEMPO}

Hay necrópolis egipcio-faraónicas en cuyas tumbas se han encontrado centenares de figuritas momiformes construidas con diversos materiales y denominadas «usabtis» y que son los objetos más importantes (junto con los escarabeos del corazón) del culto funerario del Egipto faraónico.

¿Qué significa esto? ¿Simplemente se trata de una «cuestión social»; es decir, un modo de distinguirse el rico y poderoso que se permite disponer de una legión de servidores en el "más allá", mientras el humilde y pobre no puede pagarse la confección de un usabti que trabaje y uresponda» por él? Algo hay de eso.

De los conocimientos actuales sobre esta materia parece desprenderse que ia función del usabti varió con el transcurso del tiempo a medida que variaron los conceptos religiosos y se fue complicando la teología faraónica. Al principio cabe que se tratara de una ofrenda votiva, una especie de "garantía» que asegurara la resurrección del difunto si nos guiamos por varios modelos que nos han llegado de la XII dinastía, en época de Amenenhet $111^{\circ}$, o incluso quizá antes, si la cronología fuese correcta y si fuese cierta la teoría de que el usabti perteneciente al escriba mayordomo «Dj3f» (Djaf), hijo de Mentuhotep, fue Mentuhotep II ${ }^{\circ}$ (2061/2010 a.C.) o Metuhotep $\mathrm{II}^{\circ}(2010 / 1918$ a.C.) y que se conserva en el Museo de El Cairo, pudiendo entonces retrotraer la aparición de esa costumbre a la XI dinastía; es decir, al comienzo del Imperio Medio.

Más tarde, pero aún en el Imperio Medio, comienza a emplearse el uso del capítulo VI del Libro de los Muertos ${ }^{3}$ (fig. 1), empleando la frase genérica «para no trabajar en el otro mundo», con la que la función del usab-

3 Osiris (aquí se ponia el nombre del difunto) justificado debe decir: ;Oh, estas usabtis! Se ha llamado al Osiris... justificado (a realizar) cualquier trabajo (que debe ser) realizado en la necró- 


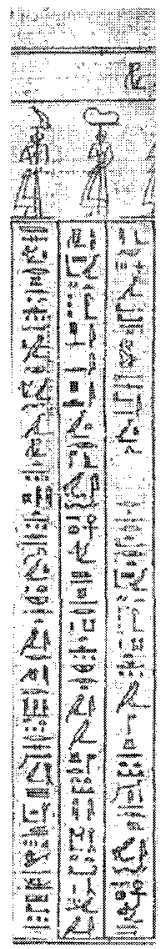

Fig. 1.

ti pasa, de ser un elemento garante de la resurrección del difunto, elevándole del mundo inferior a la contemplación de Ra, cuando asoma por el horizonte y sigue el camino del cielo hasta el ocaso, a ser un elemento neutralizador de la responsabilidad que tiene la momia, una vez «justificado» el difunto (es decir, superado el paso de la pesada del corazón o psicostasia sin encontrar en él iniquidad alguna) a trabajar en las tierras del otro mundo. De ahí que los usabtis más evolucionados, no los primeros, que carecen de extremidades superiores y manos que porten la azuela y el saco de grano, útiles imprescindibles para el trabajo en el campo, presentan estos útiles.

polis, ¡He aquí! Cualquier oposición será eliminada (por él) alli por un hombre bajo él. Decid: ¡Héteme aqui (cuando) os llamo! Prestad atención a todas horas para trabajar allí, para arar los campos, para rellenar los canales con agua, para transportar arena del Oeste al Este. Decid: ¡Héteme aquí! ¡Osiris... justificado! (Traducción del papiro de Turín por Boris de Rachewiltz). 
También es probable que ya en las últimas dinastías los usabtis se utilizaran más bien como una "vieja costumbre sentimental» de acompañamiento al difunto, pero sin una firme creencia y, sobre todo, definida respecto a su concreta función.

Respecto a la expresión usabti con que conocemos en la actualidad estas estatuillas, pudiera provenir del verbo egipcio "ws.b" (usheb = responder) y, con un origen más antiguo, «sh $3 w 3 b$ " (sha wab = madera) con la que eran fabricadas las primeras figuras funerarias esculpidas y colocadas en la tumba al objeto de "responder o contestar» en lugar del difunto, sustituyéndolo así, en los diversos trabajos agrícolas a que pudiese hacerse acreedor en la otra vida. A tal objeto, como ya hemos dicho más arriba, estas estatuillas portan en sus manos los instrumentos o útiles agrícolas necesarios; es decir, el azadillo, el cestillo o saco para transportar el grano, amén de otros útiles campesinos, incluido - como no- el látigo o bastón de los capataces cuando representaban a éstos.

Muchas de estas estatuillas son anepígrafas o, en todo caso, se encuentra simplemente grabado el nombre del difunto. En otros casos, y a partir de la época clásica, llevan grabado un texto mágico, consistente en una porción o síntesis del capítulo $\mathrm{V} 1$ del Libro de los Muertos. $\mathrm{Y}$, en virtud del encantamiento que porta, el usabti cobrará vida en el momento preciso de ser conminado a realizar el trabajo con el "otro mundo».

A lo largo del Imperio Medio la costumbre funeraria y religiosa fue colocar en la tumba un solo usabti por difunto o momia; es decir, un verdadero "doble" del "justificado" 4 . Más tarde se colocaron varios usabtis en la tumba lo cual, presumiblemente, indica que las ideas religiosas iban

\footnotetext{
4 La teología epigcia, probablemente a partir del Imperio Medio, conocía un «Tribunal de los muertos» presidido por Osiris, divinidad originaria de Busiris, que aparece como el «dios salvador" que garantiza la inmortalidad y que acaba convirtiéndose en la imagen del faraón difunto primero y, luego, en la imagen momiforme osiríaca de los usabtis y también de los sarcófagos, unos y otros de sospechosas similitudes.

En este tribunal se encuentra como "pesador» de la balanza Anubis, dios con cabeza de perro o chacal que preside los embalsamientos. Dicha balanza si está en el fiel, «justifica» al difunto. De ahí las tan frecuentes expresiones de «justificado» 0 «justo de voz». El término egipcio es «m3ç khrw» (maâ - kheru). Colócase en un piatillo de la balanza el corazón del muerto y en el otro el símbolo de la diosa "M3çt», esto es; la verdad y la justicia. Allí se encuentra también el dios Toth que, representado por el cinocéfalo, anota detalladamente el resultado. Si el corazón pesa lo mismo que la pluma (Maât) el difunto se «justifica». En caso contrario, ahí está el monstruo Ammit, con cuerpo de hipopótamo o cerdo gigante, esperando pacientemente a abrir sus fauces. Por eso se elaboró una fórmula mágica que propiciara al corazón y que se inscribía en los tan conocióos «escarabeos del corazón» que se colocaban, entre vendajes, sobre el pecho de la momia.

Vid, también Alonso y RoYANo, F.: «Instituciones familiares en el Egipto faraónico». Edit. Lepsius, Valencia, 1995 y Edit. EUE, Bilbao, 1996.
} 




Fig. 2.

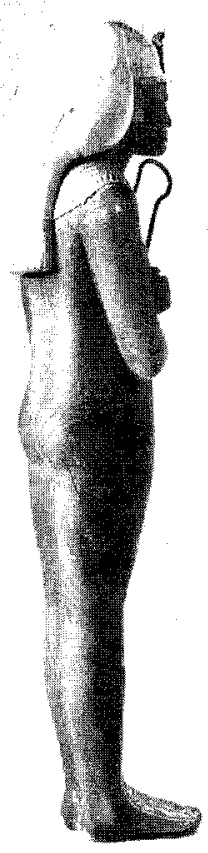

Fig. 3.

cambiando o evolucionando. Por último fueron muy numerosos los «servidores" que se colocaban junto al difunto y que, incluso, eran dirigidos por un capataz o "jefe de obreros», que se distingue en su función por tener grabado un látigo o un bastón.

Tal es el caso de los usabtis encontrados en la tumba de Tutankhamón, descubierta por H. Carter, bajo la economía del Lord Carnavon en 1922, en número de 417 y entre los que se encuentran los más bellos hallados jamás (fig. 2).

No hay más que decir que 14 de estos usabtis son de madera estucada y chapados en oro, llevando sobre su cabeza un peinado «nms» 5 (nemes), un casco ceremonial azul o la peluca «3fnt" (afnet) (fig. 3) y llevando sobre la frente los emblemas reservados, al Horus «justificado", del buitre y la cobra. Signos del Norte y del Sur; es decir «las dos tierras».

5 Era un peinado real que envolvía la cabeza cayendo sobre los hombros y espalda. 
Estos vigilantes o capataces (jefes de obreros) aparecen todos, fundamentalmente, bajo la XX|a o XXI $\left.\right|^{a}$ dinastías y desaparecen, para unos en la $X X \mid I^{a}$ y para otros en la $X X X^{a}$, aunque hay quien afirma que dura esta costumbre hasta la época ptolemaica. De cualquier modo la costumbre funeraria de la colocación de usabtis junto al féretro de la momia se ha constatado hasta la época ptolemaica.

De modo que, en su mayor parte, estas estatuillas representan trabajadores o servidores, también denominados «respondedores" (pues son quienes responden por el difunto de las obligaciones de éste, y lo sustituyen en las labores agrícolas que les puedan ser impuestas, conociéndose como ya se ha dicho, con el nombre de usabtis.

Dentro de los que portan leyendas, unos llevan nombres concretos de la momia y su oficio; sea el propio Horus (o Faraón), sean jefes de soldados, sacerdotes, primeros profetas de un determinado dios, nombres particulares, "señoras de la casa», etc.

Hasta la fecha hay clasificados, y debidamente estudiados, unos 2.000 usabtis, si bien es cierto que existen muchísimos más, a la espera de su clasificación museológica, sin contar con los que se encuentran en colecciones particulares (como, por ejemplo, la del autor).

Los primeros usabtis aparecen, como ya se ha dicho anteriormente, cerca del 1800 a.C. ${ }^{6}$, de tal suerte que puede decirse, a la luz de nuestros conocimientos actuales, que, efectivamente, los primeros usabtis elementales, momiformes y anepígrafos (fig. 4) aparecen hacia la XII dinastía, y los egiptólogos los denominamos anepígrafos precisamente por carecer de la mínima inscripción jeroglífica.

Lo cierto es que la mayor parte de estos usabtis, que se encuentran en museos y colecciones particulares son de procedencia desconocida y tampoco, por su condición anepígrafa podemos conocer a su propietario, excepto de que se tratara de una tumba inviolada, y así ponerlo en relación con otros objetos identificables hallados en la misma.

En otros casos, y cuando disponen de inscripciones, estas pueden ser muy variadas tanto por sus caracteres escriturarios (figs. 5 y 6$)^{7}$ situación topográfica en la estatuilla como por su contenido. Tal es el caso del texto

\footnotetext{
- Independientemente de la datación del usabti perteneciente al escriba «Dj3f», citado más arriba. La cronología egipcia, desgraciadamente para algunas dinastías, esta gravada por la subjetividad.

7 De la colección de usabtis del autor. $Q$ (neoegipcio, vistas de frente $(Q)$, lateral $(Q 1)$ y dorsal (Q2)). A (hierático, vistas de frente (A), lateral (A1), dorsal (A2)).
} 


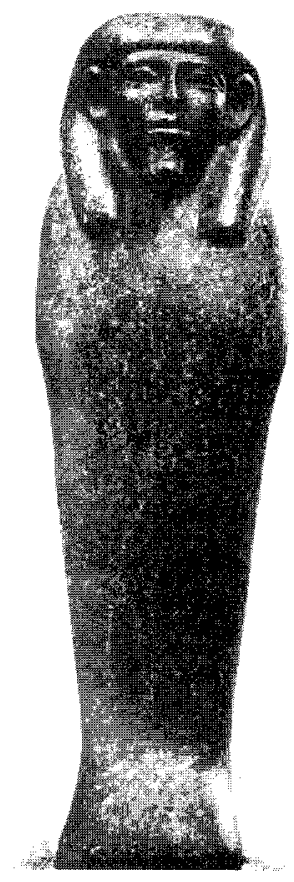

Fig. 4.
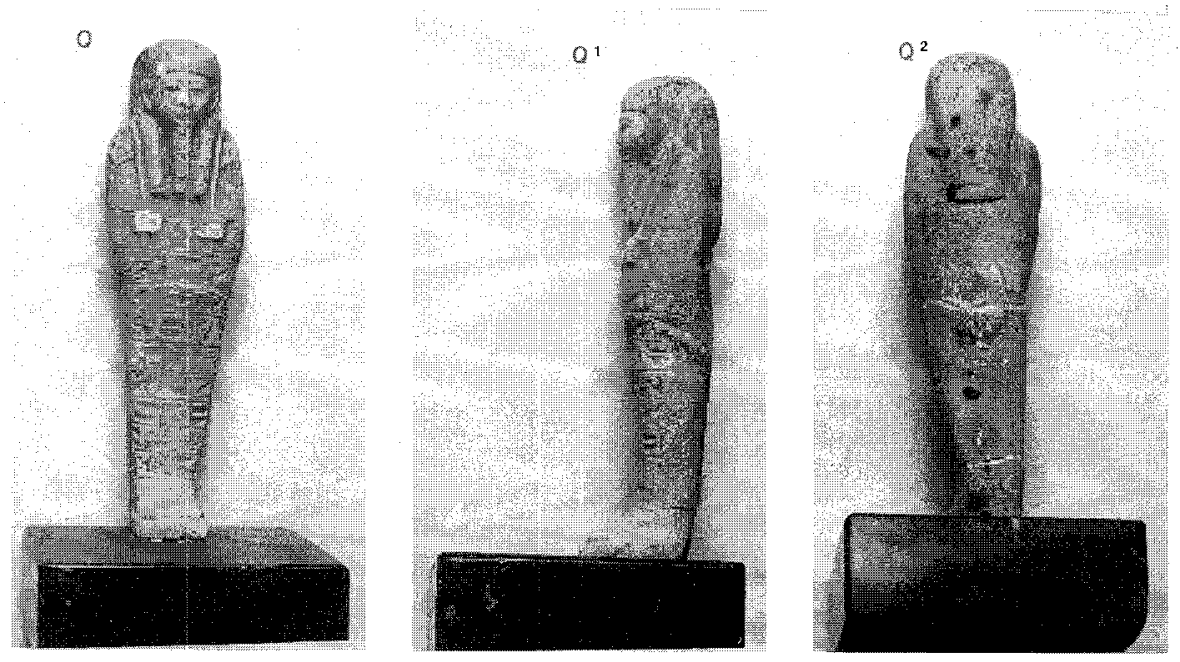

Fig. 5. 

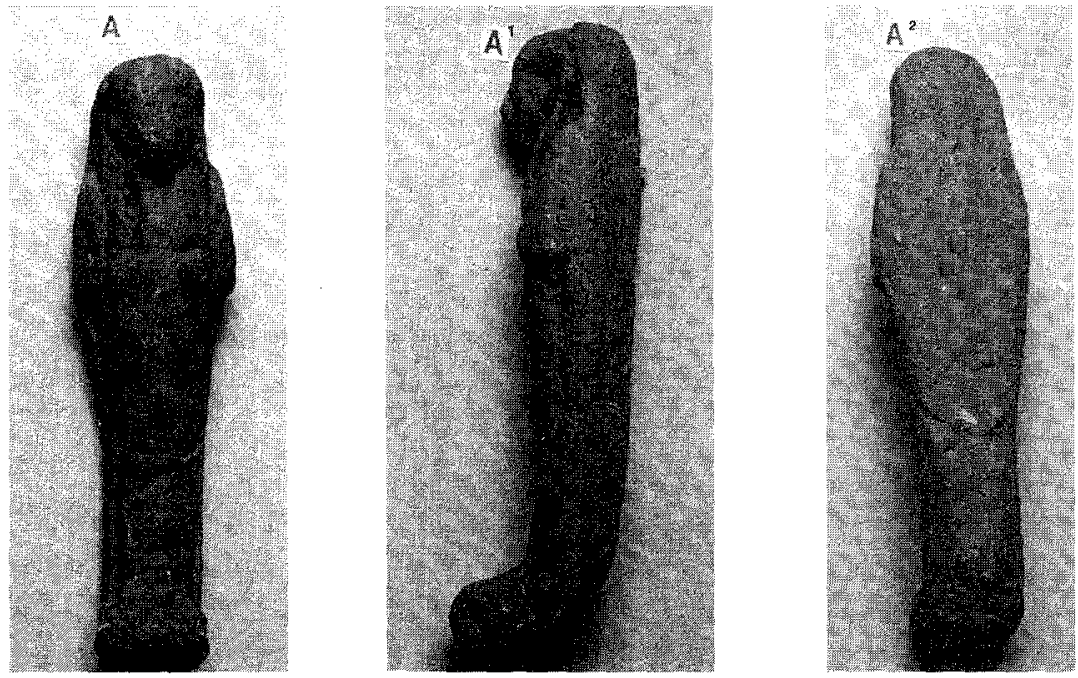

Fig. 6 .

registrado por Petrie en 1912 y que cita Aubert ${ }^{8}$ y que es copia de estelas y estatuas contemporáneas, en un usabti de $13 \mathrm{~cm}$ de altura, encontrado cerca de la pirámide de Hawara, construida por Amenemhat $111^{\circ}$ haciá 1800 a.C., y que dice:

"Ofrenda del horus a Osiris, Señor de "Djdw" (Busiris) " para que le conceda el servicio del pan y del vino al " $k 3$ " 10 de la señora de la casa "Hnwt-Nfrt" (Genutnefret) justificada".

$Y$ otro de $24 \mathrm{~cm}$ que tiene grabado el siguiente texto:

"Oirenda del Horus a Osiris, Señor de "Rst3w" (es decir, la necrópolis donde se depostó la momia) para que conceda al jefe de la ciudad "Iwnfr" (lunefer) elevarse del "Dw3t" (Duat, es decir el mundo inferior ${ }^{11}$ o mundo de los muertos), y contemplar a Ra, aquel que asoma por el horizonte».

\footnotetext{
8 Aubert, J. F. y L.: Statuettes égyptiennes: Chaouabtis/Ouchebtis. Librairie d'Amerique et d'Orient. A. Maisonneuve. París, 1974.

9 Es el nombre griego con el que se designa «3ndjt» (Andjet) 0 "Djdw» (Djedu), situado en una población del Bajo Egipto y que era el lugar sagrado de Osiris.

${ }_{10}$ Como se sabe uno de los elementos constitutivos del ser humano; es decir la parte correspondiente al principio de vida que encarna la fuerza vital y que se representa por el jeroglífico formado por dos brazos horizontales y los antebrazos y manos verticales formando un ángulo de $90^{\circ}$.

11 Es visitado por Ra durante su viaje nocturno - mientras está oculto el sol-y difundir la vida entre los justificados que allí residen.
} 
Aunque no conocemos la fecha aproximada, Aubert se inclina por dar la de ese Horus, o poco después, dada la inscripción que describe la imagen de la resurrección y, por tanto, un concepto transcendente que no hubo en las primeras dinastías del Imperio Antiguo para la generalidad de los egipcios.

Otro tanto puede decirse del usabti de $11 \mathrm{~cm}$ perteneciente al mayordomo y escriba contable «Dj3f» (Djaf), un hijo de Mentuhotep y citado más arriba, que se encuentra en el Museo de El Cairo catalogado con el n. ${ }^{\circ} \mathrm{CG} 47640$.

O el usabti de piedra calcárea pintada de $24 \mathrm{~cm}$ perteneciente al jefe de los guardias «Snbmw» (Seneb-mu) adosado a un pilar dorsal y sobre un zócalo rectangular, que también se encuentra en el Museo de El Cairo catalogado con el $n .{ }^{\circ} \mathrm{CG} 48482$, portando una inscripción vertical que dice:

«El bienaventurado cerca de Osiris, el jefe de los guardias, Snbmw».

Y en el zócalo, a 3 columnas, se lee:

"Ofrenda que hace el Horus al "abridor de caminos" (es decir, al dios perro de Asiut y de Ábydos) el Señor de "T3djsr" (la necrópolis de Tadjeser), el dios grande, el Señor de Ábydos, para que le conceda el servicio funerario y le de el agradable soplo de la vida».

De modo que, como puede verse, los usabtis epígrafos y sin contorno de extremidades superiores, pero con los más variados textos, son generalmente de piedra calcárea pintada, o de alabastro, algunos de diorita negra o de madera embetunada pero, generalmente, todos ellos poco elaborados y, eso sí, con la concreta función de súplica resucitatoria. Eso explica lo innecesario de marcar sus extremidades superiores, ni sus manos. Su figura es exclusivamente osiríaca, elementalmente momiforme, porque su función es representar el «k3» del difunto y portar la esperanza en la resurrección, idea religiosa - como se ve- anterior a los griegos y modelo para la muy posterior religión cristiana que contiene un sinnúmero de préstamos puramente egipcios.

Vendrán, luego, en esta clasificación de urgencia, los usabtis mác elaborados, con inscripciones todos ellos, con diversos ornamentos, con las manos esculpidas en relieve y el conjunto de la figura más bello y esbelto que los anepígrafos, habiendo sido todos los de las dinastías XII y XIII, descubiertos en el Alto Egipcio, proviniendo de la necrópolis de Ábydos.

Así, por ejemplo, podemos describir el usabti de $22 \mathrm{~cm}$ perteneciente a «Nn» (Nen) jefe de los tejedores, que se encuentra en Bruselas catalogado con el $n .^{\circ}$ E-3384 y que, según la traducción de Yoyotte, dice: 
"Bienaventurado cerca de Ptah-Sokar, el jefe de los tejedores Nn, justificado, junto a Sn3nkh (Senanj, su esposa) Señora bienaventurada».

Este usabti lleva el "3nkh» ${ }^{12}$ (anj) o signo de la vida, en la mano derecha y el cetro "w3s» ${ }^{13}$ (uas) como símbolo de prosperidad en la izq.

$Y$, por último, aquellos que podemos clasificar en un grupo por contener todos el capítulo VI del Libro de los Muertos donde, sintetizado, dice:

«... (se ponía el nombre del difunto)... dice: Este usabti de... realizará por su cuenta (o en sustitución de...) los trabajos que se le ordenen (en el mundo inferior) como un hombre en su tarea para cultivar los campos, irrigar las riberas y transportar la arena del este hacia el Oeste. Así sea, diré» ${ }^{14}$.

La leyenda se grababa o pintaba (dependiendo del soporte sobre el que se escribiese) generalmente en la parte delantera del usabti y encerrada entre 7 y 9 líneas horizontales (lo más común) o a veces entre 5 y 10 (lo menos frecuente) en una o tres líneas verticales en el centro y a los lados del usabti y otras, a veces, con una línea vertical sobre el dorso de la figura.

Ejemplo de estos usabtis es el correspondiente al sacerdote, escriba de Ptah, «3khpt» (Ajpet), datado en el reinado del Horus «Wsm3r» (Usimare') (Ramsés II. 1290/1224 a.C.) (fig. 7).

Concretamente en la XXI dinastía aparecen usabtis que yo denomino «distorsionantes» porque su actitud, lejos de ser osiriana, es viva, presentando su brazo derecho extendido a lo largo del cuerpo y el izquierdo cruzado sobre el pecho, cual es el caso del usabti de "P3dmn" (Padimen, padre divino de Amón) y de "Stmkhb» (Sefmejbe, sacerdotisa del templo) (figs. 8 y 9), y en contraposición al usabti del Horus Osorkon II, en la XXII dinastía, que tiene, contrariamente, el brazo derecho recogido y el izquierdo extendido (fig. 10).

Pero no todos, ya que Montet descubrió en la necrópolis de Tanis y en la tumba de Psusenes I, un sarcófago antropoide de plata, inviolado, conteniendo la momia del «Jefe de soldados, mayordomo del templo de "Khnsw" (Jonsu)», «Wdjb3wndjd" («Udjebaundjed, de la época de Psusenes (») o «3mnmp» (Amenemep. XXI dinastía. 1095/850 a.C.) (fig. 11).

12 El principio espiritual del ser humano, con un significado de gloria y magnificencia. Su jeroglífico formado por una cruz ansata, llamada también cruz de la vida o cruz de Amón es el atributo de los dioses que condona la vida al ser humano.

13 Formado por un cayado rematado en su parte superior con una cabeza animal. Es decir, la insignia de vida de la fecundidad y la fuerza.

14 Esta traducción, aunque difiere igeramente de la que hemos dado en la nota 3, de Rachewiltz, se observará que es prácticamente idéntica, para lo que nos interesa en este trabajo. 




Fig. 7.

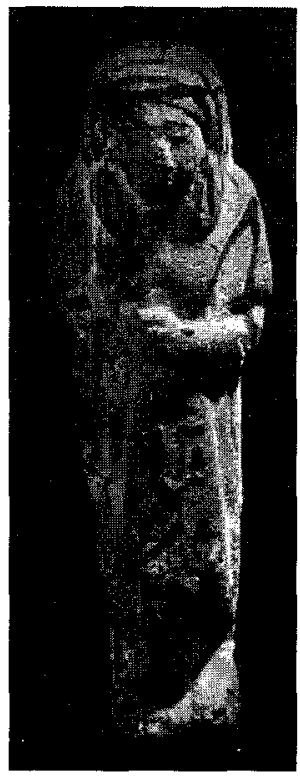

Fig. 8.

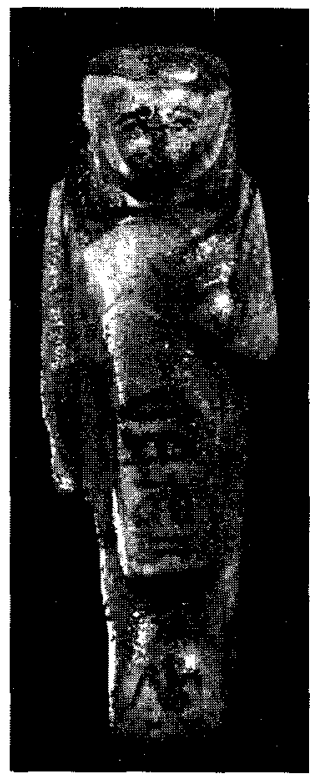

Fig. 9.

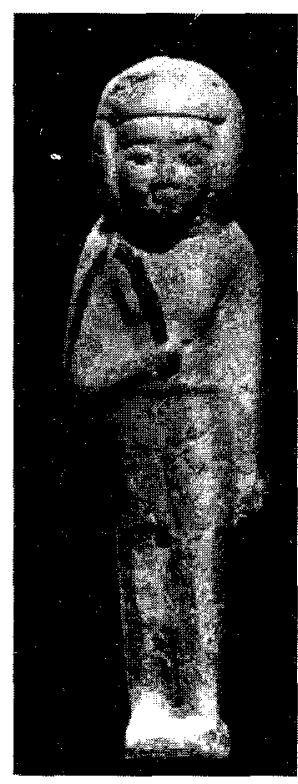

Fig. 10.

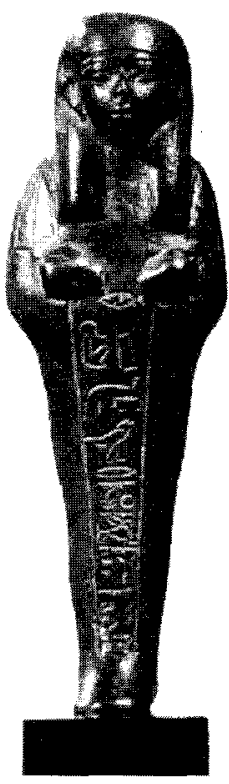

Fig. 11. 


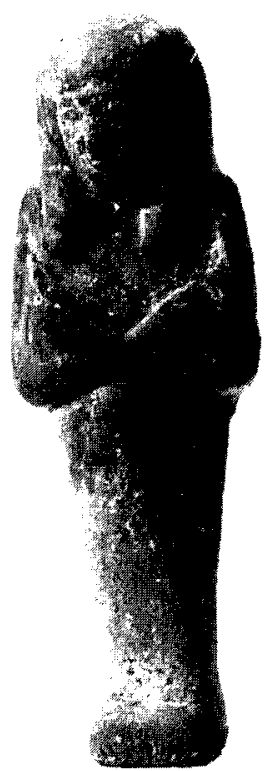

Fig. 12.

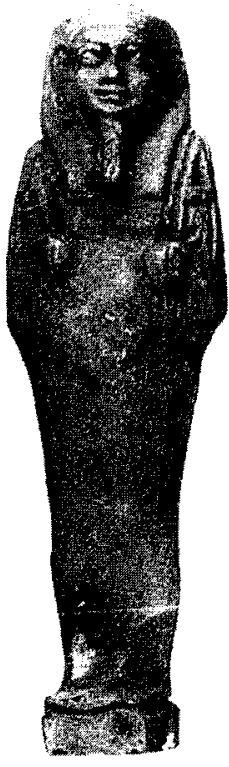

Fig. 13.

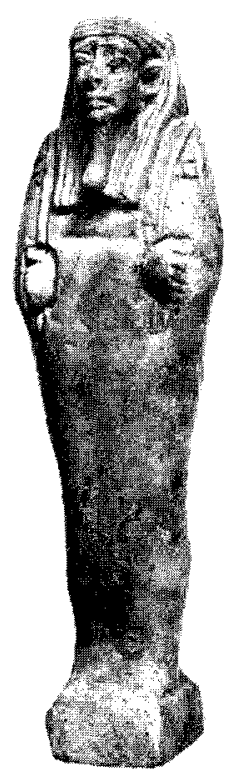

Fig. 14.

De modo que no puede darse, como regla general, que los usabtis tienen siempre una actitud osiriana; es decir, los brazos cruzados sobre el pecho, barba divina y peluca tripartita, a lo que habría de añadirse que, en contra de lo aparente, también parece que se hicieron usabtis anepígrafos en la época saíta, cual es el caso de estos tres de la XXVI dinastía (664/525) (fig. 12, 13 y 14).

La generalidad de los usabtis poseen una base cuadrangular sobre la que se apoya la figura, concluyendo el extremo podal de la misma de manera idéntica a los sarcófagos. Sin embargo conocemos uno del Museo Pincé ${ }^{15}$ donde perfectamente se aprecian los pies desnudos (fig. 15). Otro dato no menos importante es su actitud viva, lejos de la momiforme que presentan como característica todos los usabtis. Conocemos el nombre de su dueño: «P3rmhb» (Paremgeb). La figura presenta una inscripción vertical entre los pliegues del delantal, como se aprecia en la fotografía (y cuya leyenda jeroglífica se muestra al pie) que, traducida, dice: «Todo

15 Affholder-Gérard, B.: Anger, musée Pincé. Collections égyptiennes. Edit. De la Réunion des musées nationaux. París, 1990. 


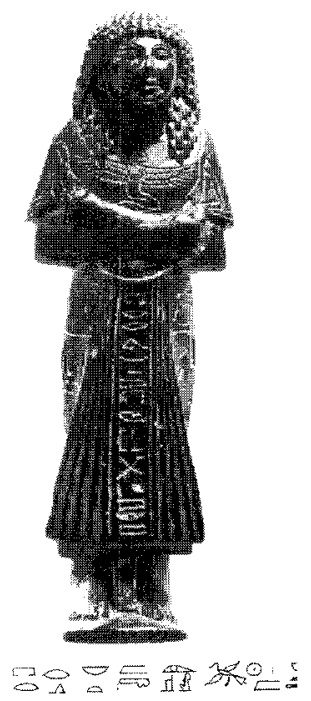

Fig. 15.

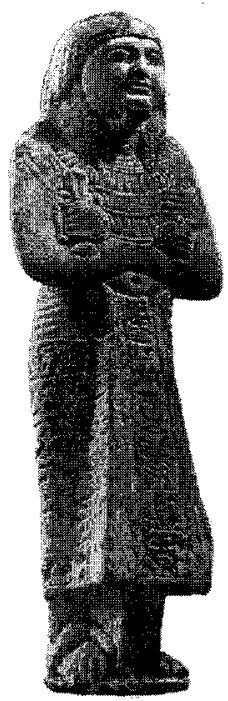

Fig. 16.

esto que ha sido ofrecido a Osiris por Paremheb». De cintura para abajo, $y$ alrededor de la figura, se encuentra grabado un extracto muy simplificado del capítulo VI del Libro de los Muertos, y que contrasta sorprendentemente con los detalles puntillistas de esta figura que perteneció a Turpín Crisé ${ }^{16}$, quien la donó al museo en 1859 , y que está catalogada como perteneciente a los comienzos de la XIX ${ }^{a}$ dinastía.

El autor de este trabajo conoce, además algunos usabtis con pies tallados, como el perteneciente al sacerdote «w3b» ${ }^{17}$ (Uab = puro) de Sekhmet, "Nkht» (Nejt) de piedra calcárea y que fue catalogado por Sotheby en diciembre de 1973 con el n. 37 (fig. 16) o los del Horus Osorkon II de la XXII ${ }^{\text {a }}$ dinastía (figs. 17 y 18) o el Gran mayordomo de Khonsu (fig. 19) jefe de soldados, "Wdjb3wjd» (Udjebaujed), o el desconocido «H3pw» (Gapu) (fig. 20).

16 Lancelot Thèodore Turpín de Crissé formó una colección muy valiosa con objetos de diversas procedencias desde 1820 a 1859 y que en lo referente a antigüedades egipcias es digno de visita. En 1858 su propietario donó a la villa de Angers su colección y a partir de 1889 se expuso en el Museo Pincé (Francia).

17 La expresión egipcia «w3b» (o " $w^{\prime} b$ " indistintamente) significa «puro», y también es el atributo de sacerdotes de bajo rango cuya fundamental misión era la purificación ritual, aunque tenían otras actividades como la de llevar a hombros la barca sagrada durante las procesiones religiosas donde se sacaba del templo la estatua del dios respectivo. 


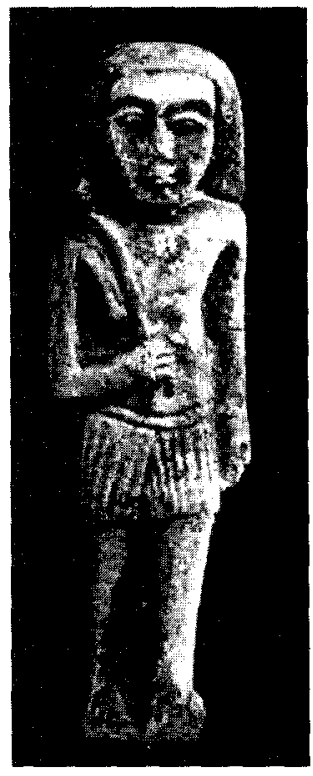

Fig. 17.

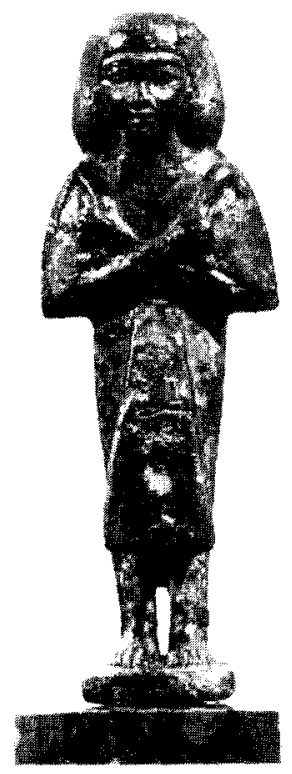

Fig. 19.

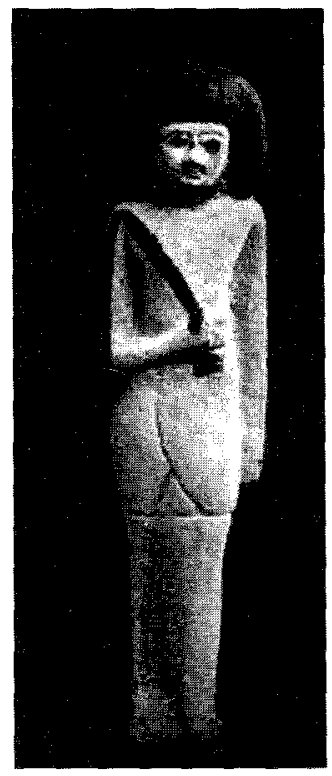

Fig. 18.

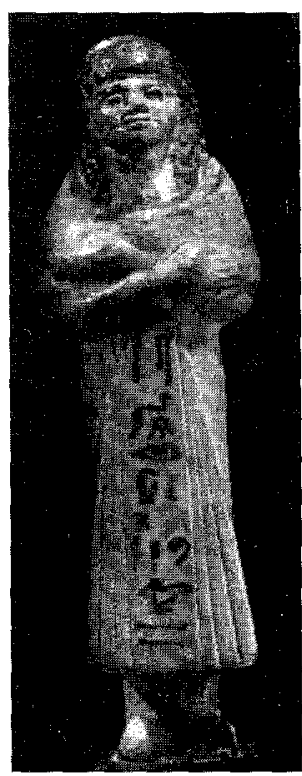

Fig. 20. 



Fig. 21.

También se conocen algunos usabtis dobles y gigantes (el autor dispone de uno falsificado comprado en Aswan (Elefantina), Alto Egipto, en la 1. ${ }^{2}$ catarata) en el Louvre, Turín o El Cairo.

Algunos usabtis auténticos de la época ptolemaica presentan una factura exclusivamente griega y no deberíamos clasificarlos como tales, aunque son "servidores" de la momia ya que portan en sus manos un pequeño cofre.

En otras ocasiones rememoran la factura saítica, si bien en esa época ya no aparecen usabtis reales y sólo corresponden a altos o medianos cargos administrativos (fig. 21) ${ }^{18}$, sacerdotes o familias acomodadas. Estos usabtis, de loza vitrificada, salidos de los talleres del Bajo Egipto suelen disponer de un rostro helenizado y grabado en su cara frontal va un texto muy cursivo, en una columna limitada por dos líneas verticales, que comienza muy alta (desde la barba hasta el extremo podal) y cuya clasificación se hace difícil, aunque parecen ser datables a partir de la XXVI dinastía.

18 De la colección de usabtis del autor. $\mathrm{C}$, vista de frente; $\mathrm{C} 1$, de perfil; $\mathrm{C} 2$, dorsal. 
Cuando Belzoni y Breechy descubrieron la tumba de Seti I, en el Valle de los reyes, pudieron cerciorarse de que esparcidos en una cámara sin decorar y de 15 metros de longitud que se hallaba detrás de la cámara funeraria, se encontraban esparcidos por el suelo más de 800 usabtis de unos $30 \mathrm{~cm}$. de altura, con los rasgos del Horus y grabada la siguiente admonición:

"Osiris, iluminador del Señor de las Dos Tierras, Men-Maatre el justificado, di: ¡Oh tú, usabti!, si el Osiris, hijo de Re, Seti el justificado, es Ilamado para hacer un trabajo en el mundo inferior como labrar los campos, regar las riberas o llevar la arena del este al oeste, para no traer calamidades cuando sea llamado, tú di: ¡Atiende, estoy aquí!»

Sabemos de las vicisitudes por las que han pasado muchas de estas estatuillas, algunas perdidas para siempre. Tal es el caso ocurrido en 1876, en que aparecieron en los mercados europeos de antigüedades muchos usabtis de Pinedjem II. EI tráfico ilegal de objetos funerarios, entre ellos los usabtis, fue escandaloso durante el siglo XIX. Por citar uno de muchos ejemplos, sólo traeremos el de la escritora Amelia Edwars que en 1874 adquirió unos preciosos usabtis azules sacados de tumbas reales y que desconocemos a quien pertenecieron y cual fue su último destino conocido. O el que cita Romer 19: «Las señoritas Broncklehurst compraron la momia y el papiro por un precio escandaloso; y luego, al no poder soportar el olor de aquella, arrojaron al difunto al río (Nilo) antes de que terminara la semana».

Y otro tanto podemos decir de los usabtis de Amenhotep II, aparecidos en 1881 en los mismos mercados, asi como trozos de usabtis aparecidos rotos en los caminos que llevan a las tumbas del valle de los Reyes.

Por último destacar que en muchos de ellos, además de su dificultad de datación, entraña la sobreañadida de que no tenemos segura su autenticidad, o si, simplemente, se tratan de factura moderna, al aparecer en mercados de antigüedades. Algunos de estos, incluso se confeccionan en la actualidad para el turismo en el propio Egipto y su falsedad es palpable (fig. 22) ${ }^{20}$. Sin embargo hay ejemplares auténticos que tienden a confusión por presentar errores en algunos jeroglíficos, producidos por los artesanos que los construyeron y grabaron (fig. 23) ${ }^{21}$.

19 ROMER, John: «Los últimos secretos del Valle de los Reyes». Ed. Planeta. Barcelona, 1983.

20 De la colección de usabtis del autor. $\mathrm{P}$, vista de frente; P1, de perfil; P2, dorsal.

21 De la colección de usabtis del autor. B, vista de frente; B1, de perfil; B2, dorsal. 

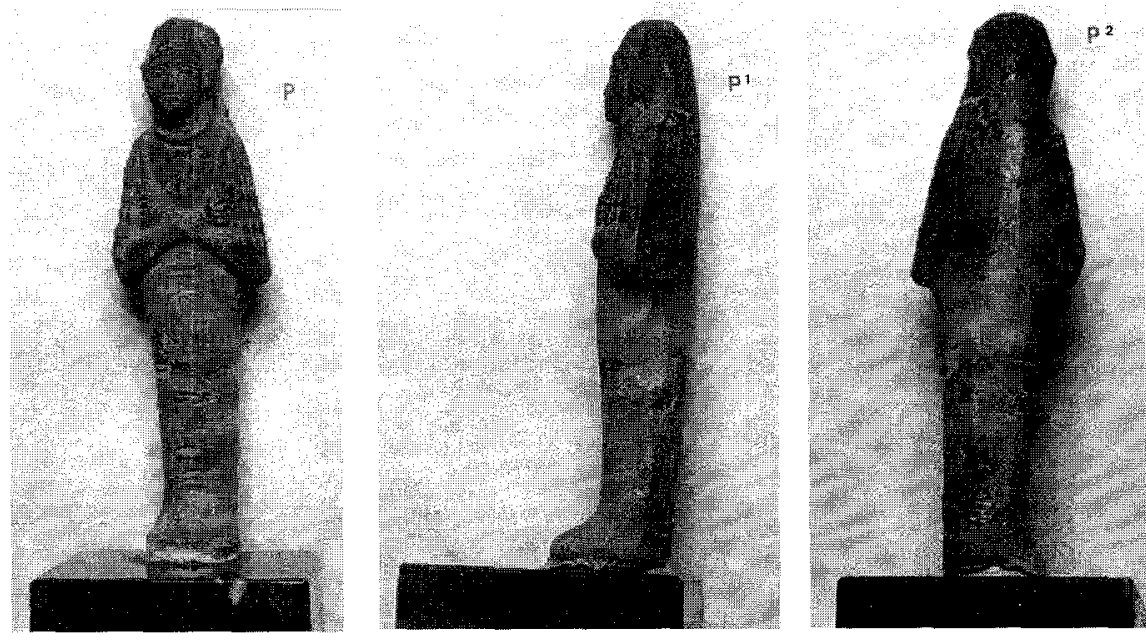

Fig. 22.
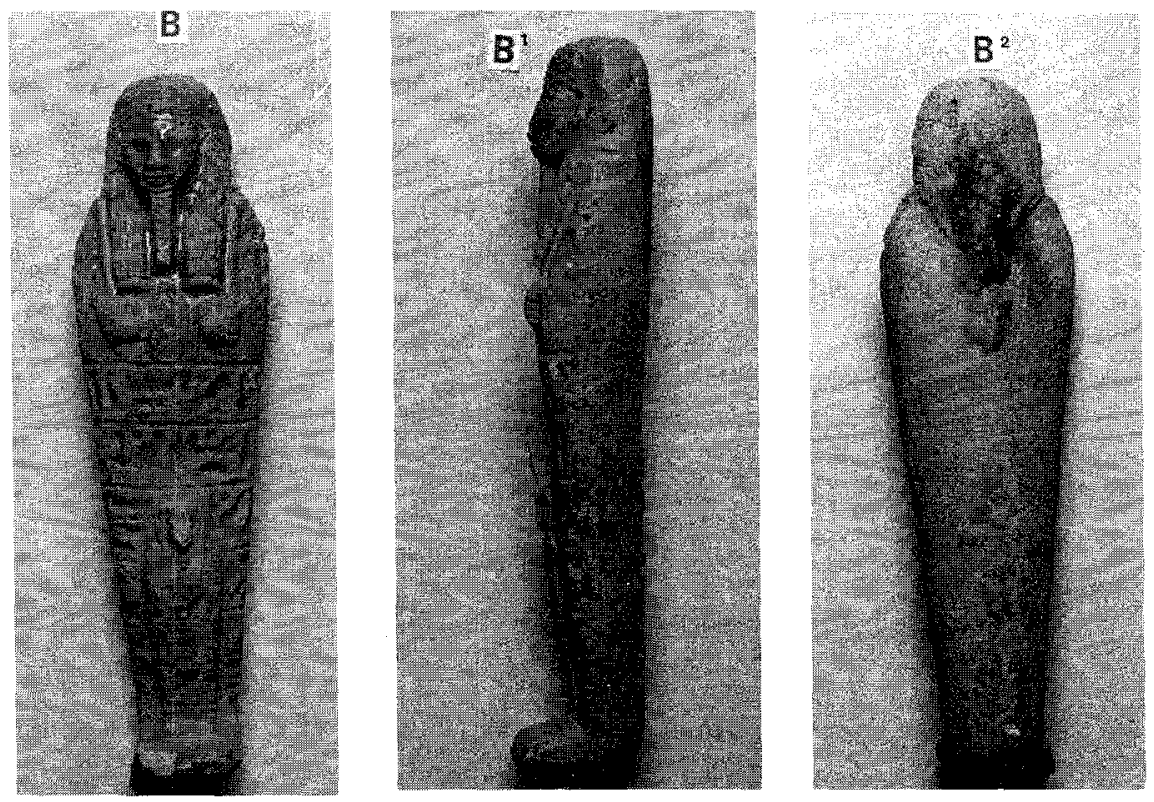

Fig. 23. 


\section{LA «JUSTIFICACIÓN» PASO PREVIO A LA DISPONIBILIDAD $D E L U S A B T I$}

Sea el usabti un doble de la momia, sea un servidor de la misma, para disponer de él es necesario ser «justo de voz». Sin «justificación» no es posible disponer del usabti. La magia de cobrar vida después de muerto no se producirá. De ahí que sólo quien esté «justificado» por medio del rito ineludible de la pesada del corazón en la balanza de la justicia ante el tribunal de Osiris puede disponer del usabti. El dios de cabeza de chacal, Anubis, observa con detenimiento el fiel de la balanza. Puesto, en uno de sus platos, el corazón del difunto y en el otro la pluma, símbolo de la diosa "M3çt», el equilibrio tiene que ser perfecto. Toth, el escriba de los dioses anota la pesada con todo detalle. Si no es así, allí está «3mmt» (Ammit) para arrastrar al muerto a los infiernos del fuego interior (figs. 24 y 25).

De modo que, para comprender la iconografía «usabtíaca» es necesario conocer algunos de los protagonistas del «juicio de Osiris» y toda su parafernalia que, al fin y a la postre, no será otra cosa que el simbólico reflejo celeste (como en lo que concierne al humano: «Lo que está arriba es como lo que está abajo") del desarrollo del procedimiento judicial humano ${ }^{22}$. Es pues necesario indicar un desarrollo elemental de los principales protagonistas del eterno drama de la muerte y su dualidad: «Persistir o dejar de existir».

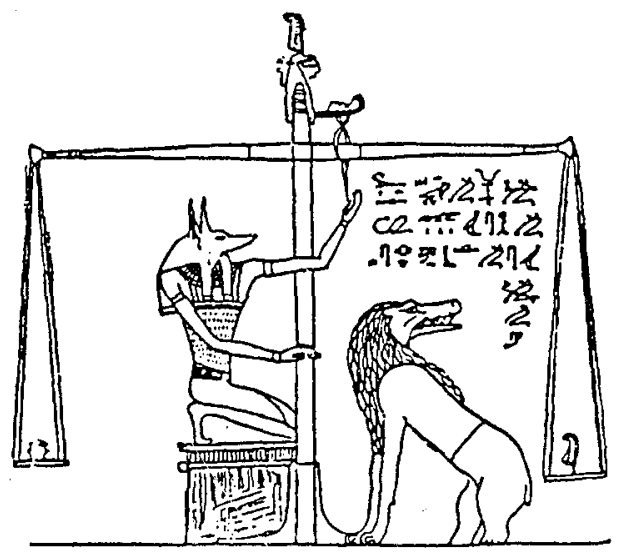

Fig. 24. El Pesaje del corazón. (Del Papiro de Hu-Nefer).

22 Vid. nota 4, in fine. Alonso y Royano. 


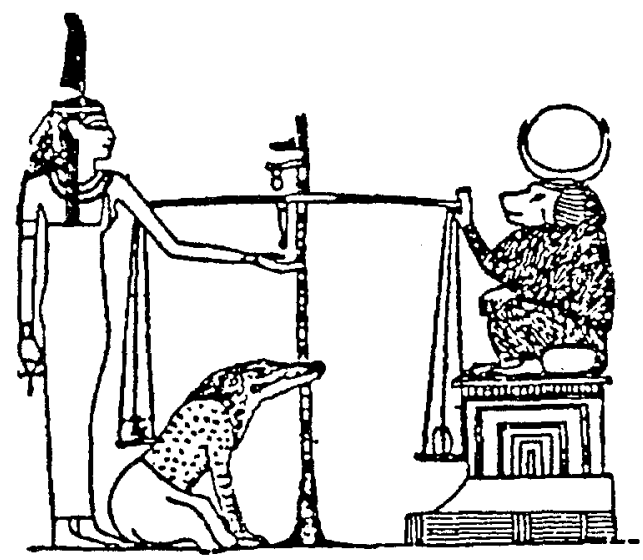

Fig. 25. El Pesaje del corazón. (Del Papiro de Quena).

\section{a) El «Orden Cósmico»: M3çt}

El concepto de "M3çt» (Maat) interpretado como "Orden Cósmico" juega, para Assmanr ${ }^{23}$ un papel tan importante como el de hacer de "eje axial»; es decir, el prototipo de una filosofía prehistórica, hasta el punto de encontrarse como noción en toda la documentación que nos ha llegado de Egipto a lo largo de toda su civilización.

M3çt, representada como un ser de sexo femenino, pertenece al panteón de dioses egipcios y, a través de los tiempos, fue unas veces hija, y otras madre de Ra, y figura como compañera inseparable de Toth, escriba de los dioses y "señor de la verdad», asistiendo a la psicostásis o "pesada del corazón". El capítulo CXXV de "rw nw prt $\mathrm{m}$ hrw" (ru nu peret me geru) o "capítulos para salir a la luz» ${ }^{24}$ (fig. 26) contempla al «Señor de la sala de las dos m3çt, y que corresponden a sus ojos; es decir, a la "visión justiciera».

Como palabra no se puede traducir, y a modo de acercamiento podríamos decir que es "verdad", «justicia", "orden". Como dice Anthes ${ }^{25}$ "la paráfrasis de M3çt podría tener dimensiones de una verdadera Kulturges-

\footnotetext{
${ }^{23}$ Assmann, J.: Maât, l'Egypte pharaonique et l'edée de justice sociale. Julliard Alerçon (Orne. France).

${ }^{24}$ Entre las publicaciones en lengua española, cabe destacar a los siguientes autores, y cuyos datos completos figuran en el índice general: Rachewiltz, Wallis Budge; y la poética, que sigue a este último autor, de Laurent.

25 Anthes, R.: Die Mâat des Echnaton von Amarna. JAOS (supl. N. ${ }^{\circ} 14$ ) 1952; pág. 2, n. $^{\circ} 3$.
} 


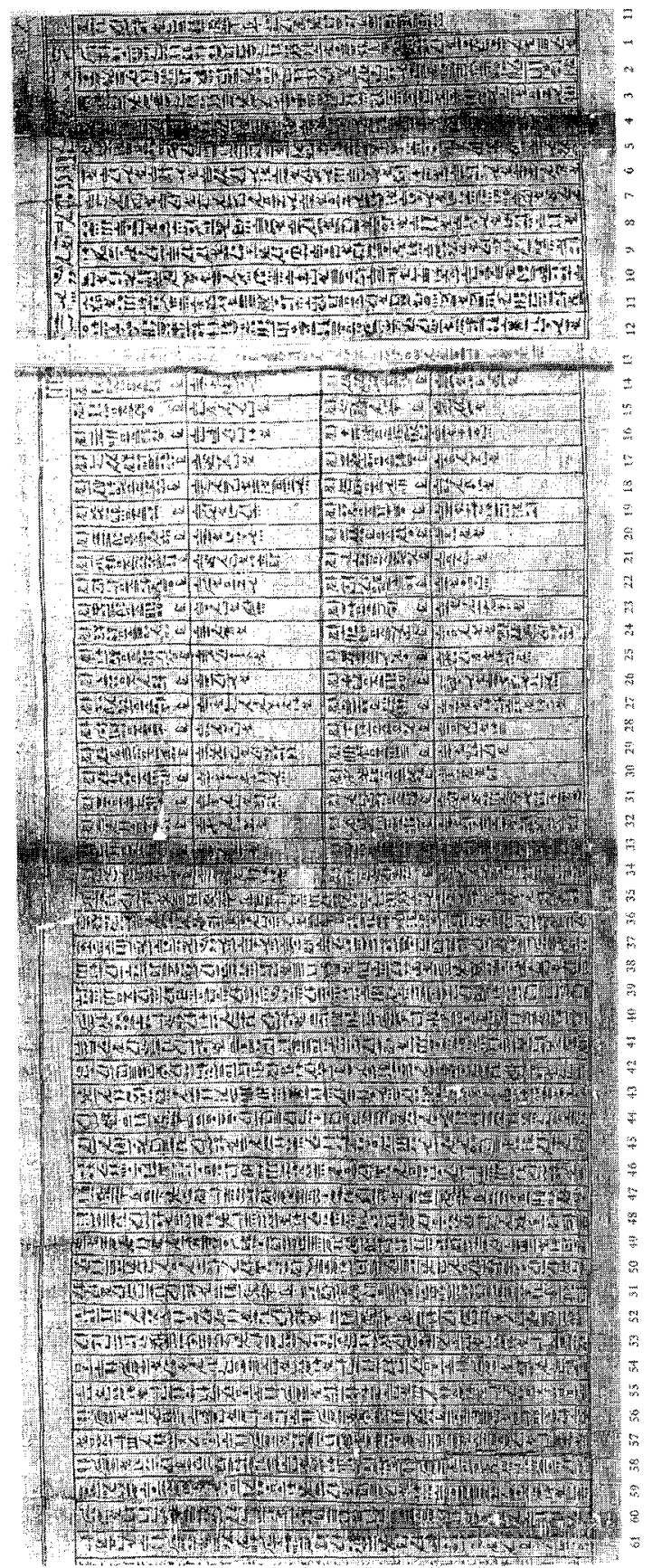

$\stackrel{\circ}{\circ}$ 


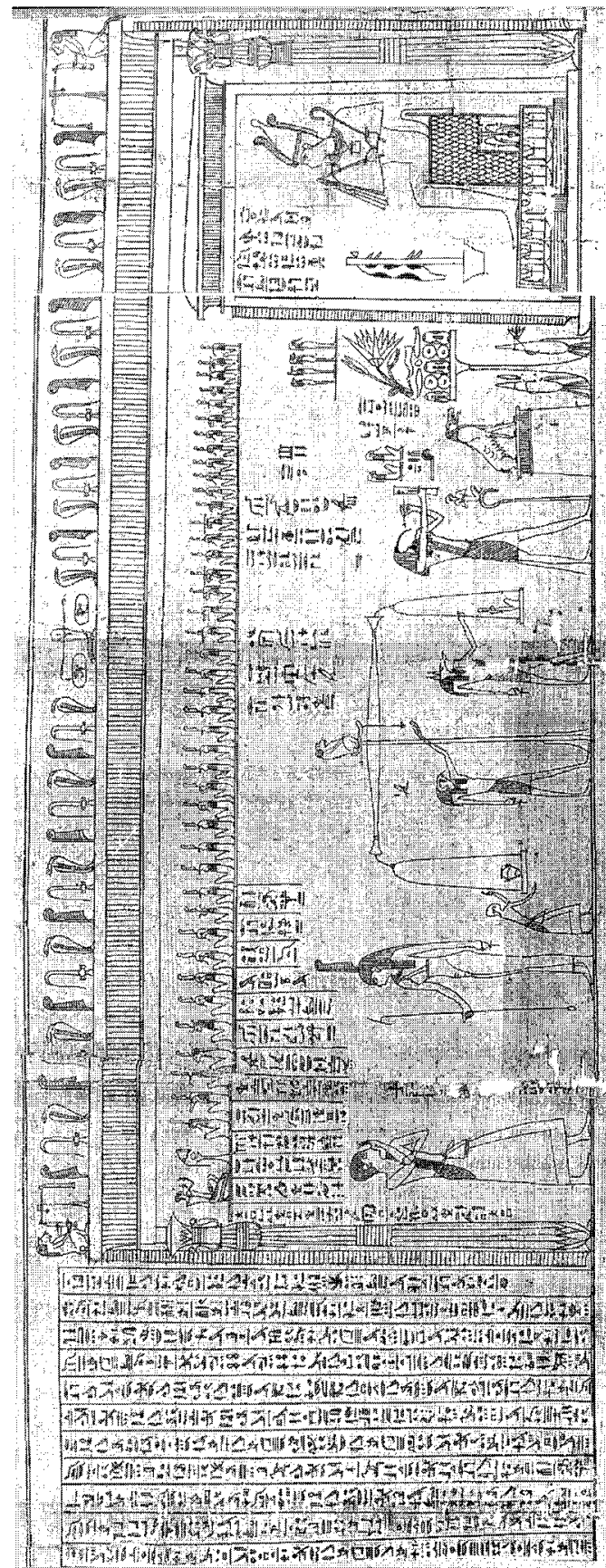


chichte egipcia». Pero aceptar este concepto significa englobar nociones como verdad, autenticidad, justicia, orden, sacrificio, e impide limitarla a una expresión puramente semántica. De tal suerte que podemos decir que M3çt es el "centro" de la ética y ésta es el "centro» de M3çt. Así pues M3çt está, tanto en la naturaleza en sí, como en la sociedad, desde el mismo momento de la creación del mundo, como un todo armónico, y de ahí derivan las nociones de derecho, orden, justicia y verdad. De modo que ella es el orden cósmico o universal, reuniéndose en su esencia el «ser» y el «deber» ${ }^{26}$ de la naturaleza y de la sociedad. La naturaleza «es» el orden cósmico universal; la sociedad «debe ser» el orden humano o ética. Esto es precisamente lo que le hace decir a Parsons ${ }^{27}$ que las primeras civilizaciones, como sociedades cosmológicas viven en un universo «socio-cósmico». Así que, el concepto «orden universal» o Weltordnung, aparece como principio regulador que gobierna el cosmos y el mundo humano, la naturaleza y la cultura, siendo un elemento esencial del discurso teórico en las disciplinas socio-antropológicas. De tal suerte que la teoría moderna ha llegado a descubrir el principio común y fundamental de las primeras civilizaciones que, precisamente en Egipto, se personaliza en M3çt.

Primero Derchain ${ }^{28}$, y después Frankfort ${ }^{29}$ trabajarán sobre el concreto papel que el Horus tiene para el mantenimiento del orden cósmico. Y para Assmann ${ }^{30}$ el concepto de M3çt será la gran creación del Antiguo Imperio, y fue el centro de su organización política como idea unificadora por la que podía mantener a los egipcios que habitaban el valle nilótico desde el delta hasia la primera catarata, bajo un dominio común. Así puede decir Bergman ${ }^{31}$ que M3çt es «el mito fundamental del Estado". Y ya, desde tan lejanos tiempos M3çt será la ley por la cual el mundo existe en armonía y por la fuerza creativa de $\mathrm{Ra}$, su padre, impidiendo el caos primordial.

\section{b) El jeroglifico $\mathrm{M} 3 c ̧ t$}

Dice Gardiner ${ }^{32}$ que el lenguaje egipcio está relacionado no sólo con las lenguas semíticas (hebreo, árabe, arameo, acadio, etc.), sino también

Miles de años antes de enunciar Kelsen su «deber ser» jurídico.

PARSONS, T.: Societies. Englewood Cliffs. New Jersey, 1966.

DeRChaIN, Ph.: El poder y lo sacro. Bruselas, 1962 (págs. 61/73).

FRANKFORD, H.: Kinghip and the Gods: A Study of Near Eastern Religion as the Integration of Society and Nature. The University of Chicago, 1948.

30 Assmann, J.: Mâat, l'Egypte..., vid. nota 18.

31 Bergman, J.: "Zum "Mythus vom Staat" im alten Ägypten", en H. Biezais (de.) The Myth of the State (Scripta Instituti Donneriani Aboensis VI) Stockholm, 1972.

32 Gardiner, A. H.: Gramática egipcia. Lepsius. Valencia, 1995. 
con las del Este de África (gala, somalí, etc.) y con las lenguas berberiscas del norte de ese continente.

En parecidos términos se expresa Lefebvre ${ }^{33}$ al enmarcar la lengua egipcia en la familia camito-semítica; es decir, un primer grupo semítico, un segundo líbico-bereber, un tercero kusítico, y un cuarto egipcio.

En ese sentido ya, Lepsius había clasificado los tres últimos grupos como camíticos y considerados como el producto de la fusión más o menos completa de hablas africanas primitivas y autóctonas con las protosemíticas que penetraron en la parte nororiental de África a finales de los tiempos protohistóricos desde la península arábiga.

Nuestra opinión ya fue expresada hace unos años ${ }^{34} \mathrm{y}$ no ha variado en absoluto. Estamos, por tanto, de acuerdo con mi querido amigo el profesor Iniesta ${ }^{35}$, lingüista por formación académica y africanista riguroso y que sigue a Cheikh Anta Diop ${ }^{36}$ en su convencimiento de la negritud egipcia, así como el profesor Martín Bernal ${ }^{37}$, incluida la lengua. $Y$ como también expresé suficientemente ${ }^{38}$, el Coloquio de la UNESCO ${ }^{39}$ ha sido clarificador y zanja, definitivamente, la cuestión.

Ya en ese Coloquio ${ }^{40}$, el profesor Obenga expresó que el parentesco entre el egipcio faraónico y las actuales lenguas negras, entre otras el wolof, no es tipológico o casual, sino genético u original. Ya Hjelmslev diferenció el parentesco lingüístico tipológico y el genético, dado que el parentesco lingüístico tipológico se fundamenta en la concordancia estructural de las palabras y de las categorías gramaticales, sin indicar si las lenguas comparadas derivan de un antepasado predialectal común. Como dice Obenga ${ }^{41}$ : «de hecho los habitantes neolíticos y predinásticos del valle egipcio y nubio, eran negros... fueron negros quienes levantaron las

\footnotetext{
э3 Lefebvre, G.: Grammaire de l'Égyptien classique. IFAO. Le Caire, 1955.

34 Alonso y Royano, F.: Instituciones familiares en el Egipto faraónico (Tesis doctoral. UNED. Madrid, 1994).

Vid. también El derecho de familia en el Egipto faraónico. Edit. Lepsius. Valencia, 1995 y E.U.A., Bilbao, 1996

35 INIESTA, F.: Antiguo Egipto. La nación negra. Sendai. Barcelona, 1989.

36 Nos limitaremos a citar de ese autor «Nations Negres et Culture». Présence Africaine. París, 1955.

${ }_{37}$ Bernal, M.: «Black Athena. The afroasiatic roots of classical civilitation». Free Association Books. London, 1987 (Hay edición en castellano de 1993).

38 Vid. nota 28.

39 El Cairo, 1974.

40 Vercoutter, J.; Blanc, N.; Obenga, Th.; Leclant, J.: Le peuplement de l'Egypte ancienne et le déchiffrement de l'écriture méroïtique. UNESCO. París, 1978 (Hay edición española de 1983).

41 Obenga, Th.: L'Áfrique dans l'Antiquité: Égypte pharaonique, Áfrique noire. Présence Africaine. París, 1973 (pág. 102).
} 
civilizaciones egipcio-nubias prehistóricas... e históricas». «El Egipto faraónico, tanto por la etnia de sus habitantes como por su lengua, pertenece en su totalidad, desde los balbuceos neoliticos hasta el final de las dinastías indígenas, al pasado humano de los negros de África" ${ }^{42}$. Esta tesis, actualmente apenas discutida, sobre el origen y naturaleza de la civilización egipcia, la inició Diop ${ }^{43}$ en 1955. Martín Bernal ${ }^{44}$, con su modelo antiguo, la amplía en el área de influencia anglo-americana, y Ferrán Iniesta ${ }^{45}$ la difunde en España.

Ese "modelo antiguo» era el habitual entre los griegos en los períodos clásico y helenístico, y la cultura griega surgió como resultado de la colonización de egipcios y fenicios que, hacia 1500 a.C. civilizaron a los naturales del país, a los que hicieron multitud de préstamos culturales. Y Vercoutter ${ }^{46}$ distingue entre raza y cultura, y dice: «Por su lengua, su escritura, su forma de pensar, la civilización egipcia es indiscutiblemente y ante todo, africana. Incluso si ha tomado elementos culturales a sus vecinos orientales, en el curso de milenios. Respecto a la distinción entre raza y cultura, en la misma línea, Leclant ${ }^{47}$.

Sin embargo, para Gardiner ${ }^{48}$ y como ya hemos apuntado más arriba: «El lenguaje egipcio está relacionado no sólo con las lenguas semíticas (hebreo, árabe, arameo, acadio), sino también con las del Este de África (gala, somalí, etc.) y con las lenguas berberiscas del Norte de África. Su conexión con los últimos grupos, conocidos como la familia amítica, es una materia verdaderamente espinosa, pero la relación con las lenguas semíticas se puede establecer de manera clara" ${ }^{49}$. Otro tanto Lefebvre que, en el fondo, sigue a Lepsius. También Menu ${ }^{50}$ sigue las tesis de Gardiner y Lefebvre, cuando dice: «L'egyptien est una langue chamito-sémiti-

42 Vid. pág. 445 del texto de la nota anterior.

43 ChElK ANTA DIOP: «Nations Negres et Culture: de l'Antiquité négro-égyptienne aux problémes culturels de l'Afrique noire d'aujourd'hui. Présence Africaine. París, 1955 (Págs. 54/58; $107 / 111 ; 171 / 175)$.

44 MARTIN BERNAL: «Black Athena. The afroasiatic...», Vid. nota 31.

45 Vid. nota 29.

46 Vercoutter, J.: «Le peuplement...». Vid. nota 34.

47 «Le peuplement...». Coloquio de ia UNESCO. Informe de los debates (pág. 92). Vid. supra notas 33 y 34 .

48 Henderson Gardiner, A.: "Egyptian Grammar being an Introduction to the Study of Hieroglups. Oxford, 1950 (ed. Revisada). Hay edición en español.

49 Un "estado de la cuestión» fue tratado por Lefebvre en "Sur l'origine de la langue "égytien" (CE, junio 1936) pero, naturalmente, 40 años después se ha llegado a las conclusiones citadas en el Coloquio de la UNESCO. Y sigue asi en su «Garmmaire de l'égyptien classique».

50 MENU, B.: «Petite grammaire de l'égyptien hieroglyphique a l'usage des bébutants". Geuthner. París, 1989. 
que (ou afro-asiatique). Élaborèe dans la vallée du Nil au cours de la préhistoire et de la protohistoire». Y muchos años antes (1910), Wallis Budge ${ }^{51}$ seguía el "modelo ario" al decir: «Es muy probable que el sistema de escritura jeroglífica se haya inventado en Egipto, y todo el cúmulo de evidencias parece indicar que tuvo comienzo cuando las tierras egipcias fueron invadidas por ciertas tribus del Noroeste o del centro de Asia; estas tribus se asentaron en el Norte entre el Nilo y el Menfis, y en el Sur en lo que hoy conocemos como Tebas, estableciendo gradualmente su cultura y su religión en los parámetros de su nuevo hogar».

Hoy se sabe con absoluta certeza que esto no fue así, aunque Mokn$\operatorname{tar}^{52}$ guste de considerar Egipto como una absorbente "esponja» cuya consecuencia habría sido un multivario mestizaje ${ }^{53}$.

Centrada la cuestión del lenguaje como de origen negro-africano, será quizás más fácil comprender el concepto mágico-religioso y filosófico de M3çt. Ciertamente no parece haberse hecho un estudio científico de M3çt, si exceptuamos el del profesor Assmann, y ello desde un punto de vista exclusivamente filosófico. De modo que M3çt en su función jurídica está todavía por descubrir.

M3çt se representa invariablemente como una mujer que lleva colocada en su cabeza una pluma de avestruz (fig. 27), como en este bajorelieve pintado en la tumba del Horus Menmarë (Sethi I), y que actualmente se encuentra en el Museo arqueológico de Florencia, o también está representada simplemente como una pluma. El ideograma determinativo de M3çt es el de una diosa con una pluma en la cabeza: $\left\{\right.$, mientras que el de justicia es: $\sum^{\circ} \beta{ }^{54}$, y que, como se ve, participa en él la pluma. En la psicostasia, y en el momento de la pesada, siempre se coloca en uno de los platillos de la balanza, el corazón del difunto, que era donde radicaba el pensamiento,

51 Wallis Budge, E.A.: «Jeroglíficos egipcios». Ed. Humanitas. Barcelona, 1988.

52 MoкHTAR, G.: Investigador árabo-egipcio y director y autor de la Introducción al Vol. II de la "Historire Genérale de l'Afrique", editado por la UNESCO en París en 1980, como consecuencia del Coloquio de El Cairo, en 1974, y cuyo primer capitulo de la historia antigua lo escribió el profesor Cheikh Anta Diop. En síntesis, y siguiendo el Informe de los debates habidos en el Coloquio sobre el poblamiento del antiguo Egipto, para Gordon Jaquet: «la hipótesis sobre la existencia de importantes migraciones entre el Valle del Nilo y la Mesopotamia en la época predinástica y a principios del período dinástico está contrarrestada por la total ausencia de intercambios de palabras prestadas entre las antiguas lenguas de Egipto y Sumer". En el mismo sentido se manifiesta Holthoer. Pero en el período de los hicsos, y más tarde, se produjeron importantes movimientos de población que dejaron términos tomados del semita. En líneas generales, Leclant estaba de acuerdo.

53 Vid. ut supra nota 28.


según la traducción del cap. CXXV del «Libro de los Muertos» de una copia de la XVIII dinastía. 


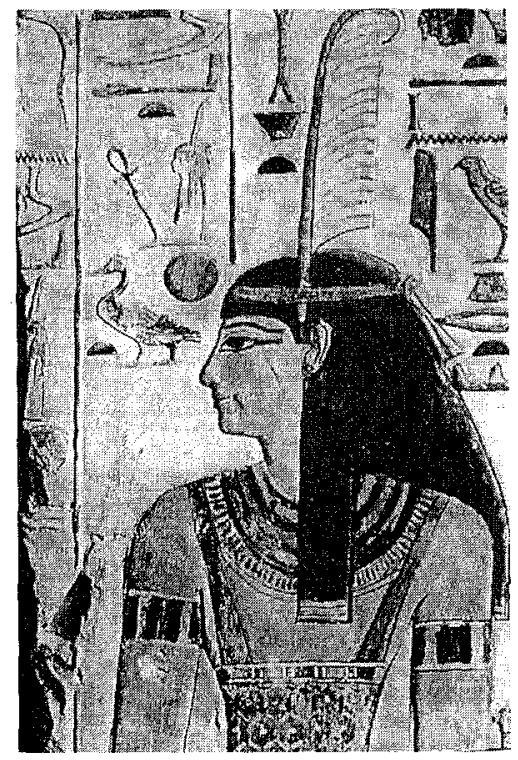

Fig. 27.
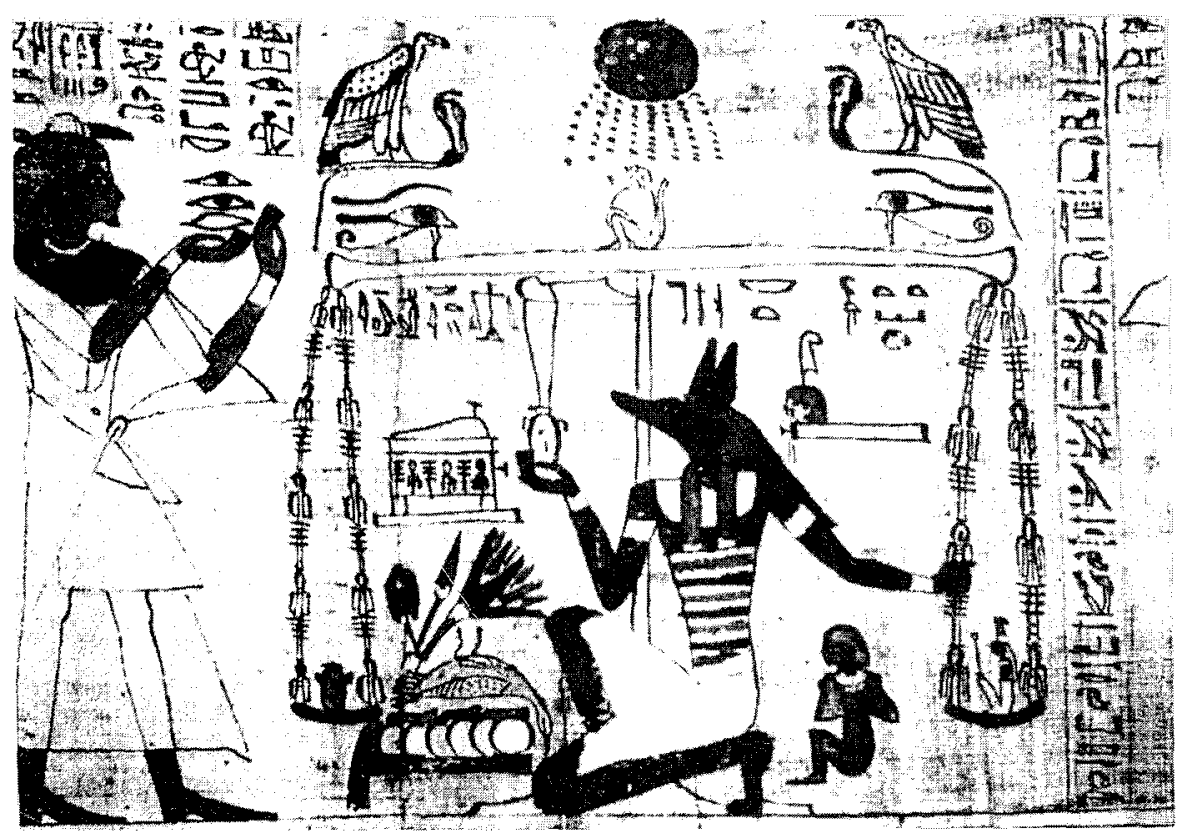

Fig. 28. 
según la teología menfita ${ }^{55}$ en el acto del juicio $\mathrm{y}$, en el otro, la pluma de M3çt (fig. 28), tal y como aparece en este pasaje ilustrado con el juicio de Osiris, del Libro de los Muertos.

El jeroglífico M3çt, como deidad antropomórfica, se representa como una mujer sentada con una pluma en la cabeza, o también solamente una pluma.

Para Gardiner ${ }^{56}$ el ideograma de pluma se lee $\beta$ «swt», y trasliterado "M3çt»; es decir, "Verdad". Fonéticamente "Sw" (Shu) es el dios del aire, hijo de Ra y esposo de «Tfnt» (Tefnut = la humedad), en la enéada de $\mathrm{He}$ liópolis, y la "verdad» tiene como característica la ligereza de la pluma. La verdad, como la bondad, no pesa. Pesa la mentira y la maldad.

El cap. CXXV del Pap. de Turín comienza con un texto para entrar en la "Sala de la Verdad y Justicia» y para separar a la persona de las infracciones cometidas («pecados») y poder ver el rostro de los dioses. Su primera línea vertical expresa: «Para decidirse: Homenaje a vosotros, Señores de la verdad y de la Justicia. Homenaje a ti, dios grande, Señor de la Verdad y de la Justicia. Yo he venido a ti, mi señor. Yo mismo he venido para contemplar tus glorias. Yo te conozco, conozco tu nombre y...» (sigue la línea vertical siguiente). Era, por tanto, necesario que el difunto hiciese una relación "negativa" de sus pecados: "no cometí iniquidad" "puse al mentiroso cabeza abajo», etc. (cap. $125 \mathrm{del}$ «Libro de los muertos»).

De modo que «M3çt» acaba siendo la esencia de la justicia, o principio primero o fundamental de la misma, por su propia esencia. Los dioses la necesitan y ella es necesaria para los humanos. Es, por tanto, una mezcla absoluta de la ética (hacer el bien y no el mal) espiritual y primicia del comportamiento social - «ser entre los otros»- del egipcio. $Y$, naturalmente, es la «idea justiciera» que se transmitirá a la cultura griega, romana y, en definitiva, a la mediterránea u occidental.

Por otro lado el «tjaty" (Jati) como "alter ego" del Horus, y el máximo representante de la administración de justicia, portaba un amuleto de «M3çt» sobre su pecho, colgado de su cuello.

\section{c) Anubis}

Es uno de los dioses fundamentales de los muertos y, por tanto, del trance psicostático, o pesaje (también podria decirse «pasaje», puesto que

55 En K. SeTHE: Dramatische Texte zur altägyptischen Mysterien-spielen (Untersuch., $X$ $<1928>$, pág. 59 y sgtes., se puede leer: «Es (el corazón) el que hace que se produzcan todos los (conceptos) perfectos, y la lengua es la que pronuncia lo que el corazón piensa".

56 Henderson Gardiner, H.: Gramática egipcia. Tomo II, pág. 51. Ed. Lepsius, s.l. Valencia, 1995. 
se trataba de un paso decisivo) del corazón y posterior llegada a la bienaventuranza del «más allá» evitando el «mundo inferior» 0 «mundo infernal» al que indefectiblemente llevaba Ammit, si el difunto no era «justificado" en el juicio de Osiris, como Señor del "más allá" o "Kht - 3mnt» (jhet Amenti); es decir, el Señor de Occidente. Ya que el occidente, «lugar donde se oculta Ra» es el lugar de los muertos y, además, piloto de la barca solar en que recorre el mundo inferior o nocturno.

Es la expresión griega de "3npw» (anpu) y es el dios con cabeza de perro negro o, chacal (canis lupaster). Conductor del difunto hasta el tribunal de Osiris. Probablemente los sacerdotes de su culto llevaban un pellejo curtido de perro sobre sus hombros, y los sacerdotes embalsamadores que representaban a Anubis en los ritos funerarios de la momificación se colocaban máscaras con cara de perro o chacal en el rostro para ejercer su trabajo. El único ejemplar conocido, que data del 600 a.C. se encuentra en el museo Pelizaeus de Hildesheim (fig. 29). Vistos así, humanos con aspecto de un rostro perruno, efectuando la momificación, para los vulgares creyentes era el propio dios Anubis quien realizaba dicha labor (fig. 30) ${ }^{57}$.

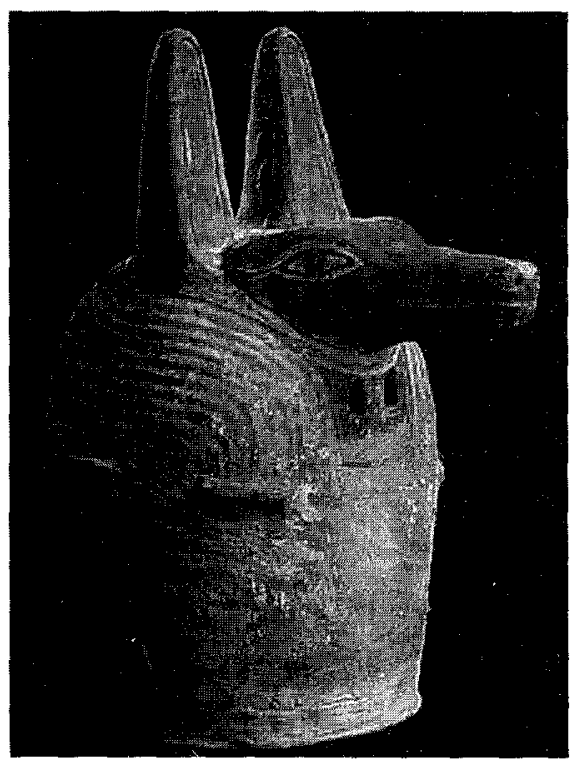

Fig. 29 .

57 Cara frontal, lateral y dorsal de 2 amuletos mortuorios del dios-chacal Anubis pertenecientes a la colección privada del autor de este trabajo. 


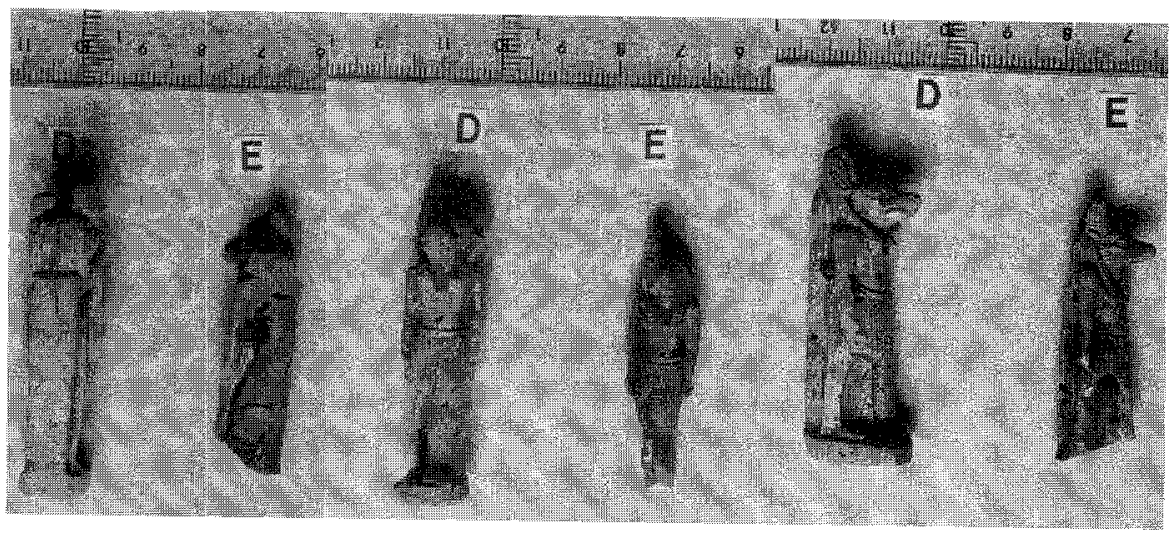

Fig. 30.

Los griegos Ilamaron Cynópolis a la antigua «k3s3» (kasa), capital del culto al dios perro.

La mitología egipcia, entre otras versiones, le hace a este dios hijo adulterino de Osiris y Neftis, esposa de Seth, que lo abandonó, siendo recogido por Isis, la «madre de todos».

Los poco versados lo confunden con el «abridor de caminos» «Wpw3wt» (Upuaut), el dios-lobo que, en los primeros tiempos era representado en los estandartes de la tropa egipcia en sus incursiones por las tierras desconocidas. Su ciudad era Siut, Licópolis para los griegos y en Ábydos fue venerado como dios de los difuntos y por tanto «Kht 3mnt" (jet Amenti), el Señor de Occidente (el "más allá»), antes de que fuera sustituido en esas funciones por Osiris.

Sin conocerse su origen ha llegado a nosotros una tableta de la época del Horus Aha que menciona su festividad y que preside el culto funerario hasta el fin de la $V^{a}$ dinastía, en que Osiris preside el tribunal mortuorio desde las más antiguas versiones en los "textos de las pirámides», donde se encuentra integrado en la Enéada heliopolitana. $Y$ en el Imperio Medio aparece embalsamado por Anubis en los «Textos de los sarcófagos».

\section{d) Toth}

A $300 \mathrm{~km}$ de El Cairo se levanta Ashmuneín, cerca de la ciudad de Toth; es decir, «Hmnw» (Gemenu). Los griegos la llamaban Hermópolis, la ciudad de Hermes; esto es, Toth. 


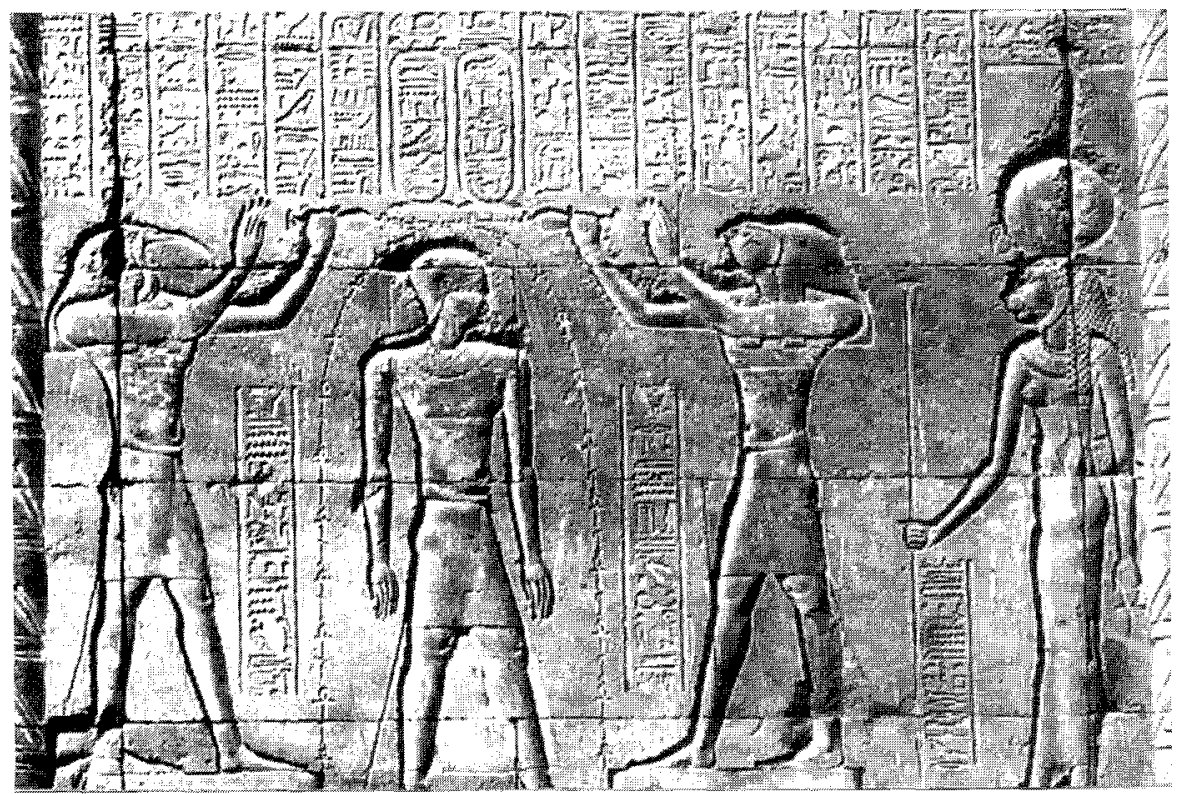

Fig. 31.

El autor ha visto en la fachada de la sala hipóstila, de 24 columnas y construcción ptolemaica, de Esna la purificación del emperador Tiberio por Toth y Harsiesis ${ }^{58}$ (fig. 31). Nótese cómo el arco protector de «3kh" (ankhs) y "W3's" (uas) ${ }^{59}$ encierra la figura del emperador romano gracias al agua vivificadora que derraman de sus jarros ambos dioses.

El dios lunar Toth, Señor de la escritura, notario y escriba de los dioses es, para García Font ${ }^{60}$, «el gran mago que supo representar en los jeroglíficos las estructuras secretas que dominan la realidad que representan». Por eso también era el «verbo creador». Para los egipcios era «dos veces grande" y los griegos, después, lo asimilaron a Hermes, denominándolo Hermes Trismegisto (tres veces grande) autor del «corpus herméticus» y de las enseñanzas gnósticas y esotéricas ${ }^{61}$ de las que nos hablan los primeros Padres de la iglesia católica.

58 El dios que se representa con cabeza de halcón, portando en su cabeza la corona «3tf» (atef); es decir, una corona ceremonial con cuernos de cordero, dos plumas y el ureus.

59 El cayado «uas» es el símbolo del poder infinito, dador de la estabilidad y la abundancia.

60 GARCía FONT, J.: Dioses y símbolos del antiguo Egipto. Ed. Fausí. Barcelona, 1987.

61 Y que gozaron de gran autoridad en los primeros siglos entre los Doctores de la Iglesia Católica, pues incluso Lactancio dijo: «Hermes ha descubierto, no sé cómo, casi toda la verdad". 
Toth es el «gran arquitecto» o demiurgo universal, señor de las ciencias y las artes, representándole unas veces con cabeza de ibis, animal ya desaparecido de la fauna autóctona y que, en ocasiones, portaba sobre su cabeza un creciente lunar y que fue el incubador del huevo cósmico. Otras veces se le representaba como un cinocéfalo o babuino sentado mostrando un largo y rojo pene en reposo y apoyado sobre el suelo.

Pero aún era más, ya que desempeñaba funciones de juez inapelable o supremo en su misión de "wpw shw" (upu sehui); es decir, "Aquel que juzga a los compañeros". De ahí la pesada del corazón en el ritual de la «justificación» del difunto.

La mitología le atribuye dos esposas: "ssht» (Seshet), a la cual se la representa con una estrella en creciente invertido sobre la cabeza y dos plumas, siendo la "señora del calendario» y su otra esposa, "Nm3wt» (Nemahuit) «la que quita todo mal» que es, en ocasiones, equivocadamente confundida con «M3çt» (Maât).

\section{e) Ammit}

«3mmt» (Ammit) o «3mmwt» (Ammut) "la devoradora», es el ser demoníaco híbrido, representante de las fuerzas del mal, con un cuerpo formado por partes de cocodrilo, león e hipopótamo. Su representación en la "pesada del corazón" (en cuyo órgano situaban los egipcios la memoria), psicostasis o “juicio de Osiris", en las escenas funerarias, es la de encontrarse pacientemente sentado observando estrictamente el fiel de la balanza para devorarlo en el momento en que el platillo donde se encuentra el corazón del muerto se incline hacia abajo o hacia arriba (figs. $24,25,26$ y 28$)$.

De modo que se va a ir creando, junto a esta figura y en la evolución teológica, una serie de atribuciones: Ammit no sólo devora al «pecador»; es decir al transgresor de las normas éticas y sociales, sino que lo tortura y lo quema con fuego, haciéndole así desaparecer para toda la eternidad e impidiéndole una vida futura "eterna" contemplando a los dioses.

Junto a Ammit, están otras potencias malignas e infernales como el detestable Apopi (conjuro VII del "Libro de los Muertos") que es una serpiente gigantesca, encarnación del mal, simbolizando la oscuridad. Esto es lo que representa el papiro de Hunefer (1379 a.C.) donde, identificado como un gato, el difunto con Ra mata a la serpiente. Es, pues, Apopi el dios serpiente del mundo subterráneo cuyo poder se opone al dios sol, Ra. 
Vemos aquí identidades sospechosas con el precepto bíblico: $3.14:$ : Y procedió Jehová Dios a decirle a la serpiente: Porque has hecho esta cosa (invitar a Eva para que coma del árbol del conocimiento del bien y del mal), tú eres la maldita de entre todos los animales domésticos y de entre todas las bestias salvajes del campo. Sobre tu vientre irás y polvo es lo que comerás todos los días de tu vida. 3.15: Y pondré enemistad entre ti y la nujer y entre tu descendencia y la descendencia de ella. El te magullará en la cabeza y tú le magullarás en el talón»; los espíritus con cabeza o rostro de cocodrilo (conjuros XXX| y XXXII, del mismo texto); los demonios-serpiente (conjuros XXXIII, XXXIV y XXXV) o simples demonios (conjuro XXXVI) ${ }^{62}$. Ciertamente en la iconografía demoníaca egipcia casi todos ellos son animales híbridos del entorno nilótico en la época a que nos remontamos: Hipopótamos, serpientes pitones, cocodrilos, cerdos, leones, etc. Son animales no humanos. $Y$ curiosamente, Ammit siempre tiene morro de cocodrilo aunque, a veces, su cabeza se adorne con una hermosa melena leonada, en otras ocasiones se trata de un cráneo de reptil.

\section{f) Osiris}

Aún cuando Erman ${ }^{63}$ basaba su antigüedad en el calendario egipcio instaurado en el 4241 a.C. lo cierto es que no aparece antes de la V Dinastía en los Textos de las Pirámides de Unas o en algunas estelas del templo funerario de Djedkare Isesi, de Busiris, por lo que originario de allí, aparece como un dios salvador y garante de la inmortalidad, siendo muy pronto identificado con el Horus (faraón) difunto.

Se trata de un dios bueno que junto a Isis, su hermana y esposa enseñó a los egipcios a cultivar la tierra y elaborar la cerveza, así como a expresar normas de convivencia y forjar herramientas con que cultivar cereales en la tierra, siendo por tanto dioses civilizadores ${ }^{64}$.

El drama de Osiris es harto conocido para repetirlo aquí, por lo que sólo indicaremos un breve resumen: Tras civilizar a los egipcios, Osiris parte

\footnotetext{
62 «Salida del alma hacia la luz del día». Texto jeroglífico traducido por Wallis Budge. Ed. Kegan Paul, Trench and Trüber. Londres, 1898.

63 Erman, A.: Die Religion der Äegypten. Berlín, 1934.

64 Plutarco: Los misterios de isis y Osiris. Ed. Glosa. Barcelona, 1976: (13. "Cuando reinó Osiris, sacó a los egipcios de su existencia de privaciones y de bestias silvestres, les dio a conocer los frutos de la tierra, les dio leyes enseñándoles a respetar a los dioses. Más tarde recorrió toda la tierra para civilizarla». De Osiris dice Diódoro Sículo en Biblioteca Histórica 1, 14: «hizo ante todo perder a los hombres el hábito de comerse unos a otros, tan pronto descubrió Isis el trigo y la cebada, que crecian anteriormente sin cultivarlos confundidos con otras plantas».
} 
hacia otras tierras en su misión civilizadora, dejando a Isis al frente cle Egipto. Cuando regresó, su hermano Seth (Tifón, para Plutarco) junto con setenta y dos conjurados dio un banquete de bienvenida y habiéndose enterado en secreto de la altura de su hermano, mandó construir un cofre (sarcófago) muy ornamentado que llevó al festín y para el regocijo general prometió regalárselo a quien cupiese perfectamente en él. Todos los invitados lo probaron y nadie tuvo las medidas exactas, hasta que Osiris se extendió en el cofre y los conjurados, todos a una, se abalanzaron sobre la tapa, cerrándola y soldando las juntas de la tapa con plomo derretido tiraron el cofre al Nilo, llegando hasta el mar por la boca Tanítica del delta.

Viene luego la arribada a Biblos, la ocultación del cofre en el tamarindo, y tras diversas aventuras el encuentro del cofre por Isis y su vuelta a Egipto con él, ocultándolo inútilmente ya que Seth lo halló y descuartizó el cadáver en catorce partes ${ }^{65}$, una de las cuales, el pene, fue tirada al Nilo y comido por tres peces ${ }^{66}$.

Isis logró recoger las partes desmembradas y preparó un pene con tallos vegetales, reconstruyendo a Osiris, tras lo que se acopló carnalmente y concibió mágicamente a Horus. De modo que vemos aquí el mito de la muerte y resurrección, tras vencer las asechanzas del mal bermejo (Seth), consiguiendo así la inmortalidad y mostrando su camino a los mortales.

De ahí, también, que esté relacionado con el agua del Nilo y la fuerza fecundante de la inundación. La concepción después de muerto es el símbolo de la eterna resurrección y de los ciclos vitales. Tiene por tanto un carácter agrario y al final de la inundación los egipcios celebraban su fiesta.

\section{EPÍLOGO}

Llegados a este punto nos resta decir que el presente trabajo no es, ni muchísimo menos exhaustivo. No pretende otra cosa que, como el resto de los salidos del autor, divulgar a nivel universitario un mundo histórico, el egipcio, del que a fuerza de vulgarizaciones excesivas, a nivel universitario sólo se conoce - excepto contados ejemplos - la parte romántico-literaria, pero no científica, del Egipto faraónico. Prueba de ello son la multitud de «Historias de Egipto» que se publican en todos los idiomas al cabo del

65 Para Diodoro, en I, 21 y IV, 6: “Tifón (Seth) destrozó a Osiris en veintiséis pedazos, que distribuyó entre sus cómplices con objeto de que todos ellos sintiesen odio común y asegurarse de ese modo defensores de su reinado".

66 El lepidoto, el pagro y el oxirrinco. 
año para el pasto devorador de los lectores poco preocupados por la ciencia histórica y que acaban teniendo una estereotipada imagen, lejana de la realidad, del Egipto faraónico. Sólo interesan las anécdotas sobre los descubrimientos de tumbas, las peripecias de sus descubridores y la estereotipada visión pseudohistórica del «Egipto milenario». Lo «otro», lo científico es demasiado arduo para adentrarse en él, sobre todo si, como en el caso de Egipto, tropezamos en demasiadas ocasiones con una carencia amplia de documentación y cuando ésta existe, gran parte aún no está debidamente estudiada y traducida.

Sin embargo, ciertamente, gracias a esa vulgarización el común de las gentes de mediana cultura "conoce algo" sobre el Egipto faraónico. Es menester, pues, divulgar a nivel universitario, con un mínimo de rigor histórico, algunos aspectos - los más llamativos, y menos áridos, si se quiere- de esa cultura que, a pesar de los esfuerzos de algunos historiadores por negarlo, ha influido vastamente sobre la posterior cultura griega y después romana, hasta erigirse en norte cultural de nuestras ideas religiosas, arquitectónicas, jurídicas y sociales, impregnadas de mitos, símbolos y creaciones egipcias. La iconografía religiosa católica, por ejemplo, no puede evadirse de modelos egipcios: Isis con Horus niño en brazos o amamantándolo es María con el niño Jesús. Cristo, muy probablemente, bebió en fuentes coptas y en la magia greco-egipcia, aunque hacía años que era una provincia romana.

\section{BIBLIOGRAFÍA NO EXHAUSTIVA}

AffHolder-Gèrard, B.: «Anger, musée Pincé. Collections ègyptiennes». Edit. De la Réunion des musées nationaux. París, 1990.

Alonso y ROYANO, F.: «Instituciones familiares en el Egipto faraónico». Edit. Lepsius, s.I. Valencia, 1995, y Edit. EUE. Bilbao, 1996.

- "Análisis jurídico de "in n.ï $r$ i'sw"». E.T.F. Serie II, n. ${ }^{\circ}$ 8. UNED. Madrid, 1995.

- «La ciudad y el ciudadano en Egipto». E.T.F. Serie II, n. 10. UNED. Madrid, 1997.

ANTHES, R.: «Die Maât des Ecrnaton von Amarna». JAOS (supl. N. ${ }^{\circ} 14$ ), 1952; pág. 2, n. 3.

ASSMANN, J.: "Maât, l'Egypte pharaonique et l'edée de justice sociale». Julliard Alerçon (Orne. France).

AuberT, J. F. y L.: «Statuettes ègyptiennes: Chaouabtis/Ouchebtis». Librairie d'Amerique et d'Orient. Maisonneuve. París, 1974.

Bergman, J:: "Zum "Mythus von Staat" in alten Ägypten". H. Biezais (de.) "The Myth of the State. Edit. Scripta Instituti Donneriani Aboensis VI. Stockholm, 1972.

BERnAL, M.: «Black Athena. The afroasiatic roots of classical civilitation». Edt. Free Association Books. London, 1987.

Cimmino, F.: «Vita quotidiana degli egizi». Ed. Rusconi libri. Milano, 1985.

CHEIK ANTA DIOP: «Nations Negres et Culture: de l'Antiquité négro-égyptienne aux problémes culturels de l'Afrique noire d'aujourd'hui. Edit. Présence Africaine. París, 1955.

Daumas, F.: «La civilisation de l'Egypte pharaonique». Ed. B. Arthaud. París, 1965.

- «Les dieux de l'Egypte». Ed. Presses Universitaires de France. París, 1977.

Derchain, Ph.: «El poder y lo sacro». Bruselas, 1962. 
Desroches-Noblecourt, C.: «Toutankhamon». Ed. George Rainbird Itd. Londres, 1963.

Diódoro Siculo: Biblioteca histórica. Ed. Clásicas. Madrid, 1995.

Drioton, E. y VAndier, J.: L'Egypte. Edt. Presses Universitaires de France. París, 1938.

FRANKFORD, $\mathrm{H}$.: «Kinghip and the Gods: A study of Near Eastern Religion as the Integration of Society and Nature». The University of Chicago, 1948.

GarCía Font, J.: Dioses y símbolos del antiguo Egipto. Ed. Fausí. Barcelona, 1987.

GARDINER, A. H.: «Gramática egipcia». Lepsius. Valencia, 1995.

- "Egyptian Grammar being and Introduction to the Study of Hieroglyphs». Oxford, 1950. Herodoto de Halicarnaso: Los nueve libros de la Historia. Ed. Iberia. Barcelona, 1960.

INIESTA, F.: «Antiguo Egipto. La nación negra». Ed. Sendai. Barcelona, 1989.

KEMP, B. J.: «Ancient Egypt: Anatomy of a Civilization». Ed. Routledge. Londres, 1989.

LAMBELET/RiEsTERER: "Das Ágyptische Museum Kairo». Zurich s/f.

LEFEBVRE, G.: «Grammaire de l'Egyptien classique». IFAO. Le Caire, 1955.

MOKHTAR, G.: «Introdution. Histoire Genérale de I'Afrique». Edit. UNESCO. París, 1980.

MÜLLER, M.: «Egyptian Mythology». Pennsylvania. S/f. EEUU.

ObEngA, Th.: «L'Afrique dans l'Antiquité: Egypte pharaonique. Afrique noire». Edt. Présence Africaine. Paris, 1973.

PARSONS, T.: «Societes». Englewood Cliffs. New Yersey, 1966.

PLUTARCO: «Los misterios de Isis y Osiris». Ed. Glosa. Barcelona, 1976.

RACHET, G.: «L'Egypte ancienne». Ed. Du Félin. París, 1987.

RACHEWILTZ, B.: «Gli Antichi Egizi». Ed. Mediterranee. Roma, 1987.

Romer, John: "Valley of the Kings». Ed. Michael Joseph and Rainbird. London, 1981.

SETHE, K.: «Dramatische Texte zur altägyptischen Mysterien-Spielen». (Untersuch, X) 1928.

Trigger, B. G. et allii: «Ancient Egypt: A social history. Ed. Cambridge University Press, 1989.

Vercoutter, J.; Blanc, N.; Obenga, Th. y Leclant, J.: «Le peuplement de l'Egyple ancienne et le dèchiffrement de l'ècriture mèroïtique». Edt. UNESCO. París, 1978.

WALLIS BuDGE, E. A.: «Jeroglíficos egipcios". Ed. Humanitas. Barcelona, 1988.

Wallis Budge: "Salida del alma hacia la luz" (texto jeroglífico). Ed. Kegan Paul. Trench and Trüber. Londres, 1898. 